\title{
Feasibility of Repeated Assessment of Cognitive Function in Older Adults Using a Wireless, Mobile, Dry-EEG Headset and Tablet-Based Games
}

\section{OPEN ACCESS}

Edited by:

Qiang Luo,

Fudan University, China

Reviewed by:

$X i$ Jiang,

University of Electronic Science and Technology of China, China

Albert Yang,

National Yang-Ming University, Taiwan

${ }^{*}$ Correspondence:

Alison R. Buick

alison@cumulusneuro.com

Specialty section:

This article was submitted to

Public Mental Health,

a section of the journal

Frontiers in Psychiatry

Received: 19 June 2020 Accepted: 18 March 2021

Published: 25 June 2021

Citation:

McWilliams EC, Barbey FM, Dyer JF, Islam MN, McGuinness B, Murphy B,

Nolan H, Passmore P,

Rueda-Delgado LM and Buick AR

(2021) Feasibility of Repeated Assessment of Cognitive Function in Older Adults Using a Wireless, Mobile,

Dry-EEG Headset and Tablet-Based Games. Front. Psychiatry 12:574482.

doi: 10.3389/fpsyt.2021.574482

\author{
Esther C. McWilliams ${ }^{1}$, Florentine M. Barbey ${ }^{2}$, John F. Dyer ${ }^{1}$, Md Nurul Islam ${ }^{2}$, \\ Bernadette McGuinness ${ }^{3}$, Brian Murphy ${ }^{2,4}$, Hugh Nolan ${ }^{2}$, Peter Passmore ${ }^{3}$, \\ Laura M. Rueda-Delgado ${ }^{2,5}$ and Alison R. Buick ${ }^{1,4 *}$ \\ ${ }^{1}$ Cumulus Neuroscience Ltd, Belfast, United Kingdom, ${ }^{2}$ Cumulus Neuroscience Ltd, Dublin, Ireland, ${ }^{3}$ Centre for Public \\ Health, School of Medicine, Dentistry and Biomedical Sciences, Queen's University Belfast, Belfast, United Kingdom, \\ ${ }^{4}$ School of Electronics, Electrical Engineering and Computer Science, Queen's University Belfast, Belfast, United Kingdom, \\ ${ }^{5}$ Trinity Centre for Biomedical Engineering, Trinity College, The University of Dublin, Dublin, Ireland
}

Access to affordable, objective and scalable biomarkers of brain function is needed to transform the healthcare burden of neuropsychiatric and neurodegenerative disease. Electroencephalography (EEG) recordings, both resting and in combination with targeted cognitive tasks, have demonstrated utility in tracking disease state and therapy response in a range of conditions from schizophrenia to Alzheimer's disease. But conventional methods of recording this data involve burdensome clinic visits, and behavioural tasks that are not effective in frequent repeated use. This paper aims to evaluate the technical and human-factors feasibility of gathering large-scale EEG using novel technology in the home environment with healthy adult users. In a large field study, 89 healthy adults aged 40-79 years volunteered to use the system at home for 12 weeks, 5 times/week, for $30 \mathrm{~min} / \mathrm{session}$. A 16-channel, dry-sensor, portable wireless headset recorded EEG while users played gamified cognitive and passive tasks through a tablet application, including tests of decision making, executive function and memory. Data was uploaded to cloud servers and remotely monitored via web-based dashboards. Seventy-eight participants completed the study, and high levels of adherence were maintained throughout across all age groups, with mean compliance over the 12-week period of $82 \%$ ( 4.1 sessions per week). Reported ease of use was also high with mean System Usability Scale scores of 78.7. Behavioural response measures (reaction time and accuracy) and EEG components elicited by gamified stimuli (P300, ERN, Pe and changes in power spectral density) were extracted from the data collected in home, across a wide range of ages, including older adult participants. Findings replicated well-known patterns of age-related change and demonstrated the feasibility of using low-burden, large-scale, longitudinal EEG measurement in community-based cohorts. This technology enables clinically relevant data to be recorded outside the lab/clinic, from which metrics underlying cognitive ageing could be extracted, opening the door to potential new ways of developing digital cognitive biomarkers for disorders affecting the brain.

Keywords: EEG, EEG biomarker, cognition, gamification, mobile EEG 


\section{INTRODUCTION}

Recent advances in digital technologies provide a wealth of opportunity in the management of health conditions. In neurological disease the heterogeneity and complexity of conditions, along with continuing reliance on traditional subjective measurement tools, have presented a challenge for the development of data-driven biomarkers for diagnosis, monitoring and prediction of therapeutic response (1-7). The suite of tools described in this paper was designed to enable longitudinal, in-home data collection of brain electrophysiology and cognitive performance. The platform comprises (1) a dry sensor, wireless electroencephalography (EEG) headset that records brain activity, (2) gamified versions of cognitive tasks, and (3) cloud-based storage and automatic processing-with the aim of identifying potential digital biomarkers with utility in neuropsychiatric and neurodegenerative disorders.

EEG directly reflects neural synaptic function, with similar patterns from animal to human (8-10) and thus has substantial potential as a brain-based, translatable biomarker for diseases such as schizophrenia (11-18), depression (19-21) and Alzheimer's disease (AD) (22-29). However, traditional research EEG setups are effortful and time-consuming, requiring expensive equipment and the support of personnel with technical training. Single or infrequent lab-based EEG recording sessions may be affected by a range of factors including fluctuations in levels of participants' mental alertness, fatigue and task-induced mental workload $(30,31)$. Similarly, cognition as traditionally measured in therapeutic research and practise tends to take the form of clinician administered batteries of neuropsychological tests [e.g., $(32,33)]$ which, whilst low burden and relatively inexpensive, are subject to variability in scores on repeated testing occasions (34). Infrequent, "snapshot" assessments are subject to measurement error arising from multiple factors, such as practise effects (35-37), the "white-coat effect" related to anxiety about suspected cognitive impairment (38), and dayto-day fluctuations in context (39), in mood and in perceived stress (40-44).

The adoption of modern technology into medicine allows for more innovative forms of data collection (e.g., wearable devices), increasing objectivity and taking advantage of powerful analytical tools to probe complex diseases. Further, digital tools may allow for more frequent sampling and detection of subtle daily fluctuations, at minimal disruption to the patient since data may be collected both inside and outside of the clinic. Progress in modern electronics and dry sensor technology means that EEG is emerging from amongst standard brain imaging methods as a mobile technology, suitable for deployment to very large cohorts for convenient at-home use (45). Likewise, neuropsychological testing can now be completed outside of the clinic through the use of automated, web-based assessments (46-49).

Mobile EEG systems are advancing quickly. Several studies have shown that it is possible in principle to collect EEG recordings using consumer-grade hardware, and from the data extract potentially useful neuronal signals, including spectral band-power measures $(45,50,51)$ and task-evoked eventrelated potentials (ERPs) (52-55). However, studies using such devices have typically required some specialist equipment (e.g., a computer running bespoke software to present stimuli and record EEG), and a specialist experimenter to set up and supervise the recording. In addition, most consumer-grade EEG platforms operate using low numbers of electrodes, leaving some research questions and certain types of analysis out of reach for researchers. To the authors' knowledge, there exists no prior example of large-scale, unsupervised in-home, repeated sampling ERP research using a dry-sensor, portable, user-friendly EEG platform.

Innovative solutions can be deployed to enable us to carry out unsupervised data collection without placing undue burden on the user, such as 'dry' sensors (i.e., eschewing the conductive gel used in the laboratory in favour of an easier electrode setup) and automated user-facing stepwise tutorials and notifications (to compensate for reduced environmental control outside the laboratory). Similarly, for use at home over repeated sessions, EEG/ERP tasks as used in research may not be particularly exciting or motivational for the user, but applying gamification can make these tasks more engaging and rewarding for participants (56) and gamified cognitive tasks can facilitate global data gathering on an unparalleled scale (57).

The study presented here was a first, proof-of-concept, field study to test the human-factors and technical feasibility of an early version of the Cumulus Neuroscience platform in a cohort of healthy adults spanning an age range up to 79 years old. In this paper we investigate the potential of this platform to capture in-home, frequent repeated measurement of EEG and behavioural metrics of cognitive ageing, metrics that also have broader appeal as potential cognitive biomarkers for the diagnosis and treatment of disorders affecting the brain. Use of the platform on a regular basis over 3 months assesses the acceptability of long-term use for future use cases where longitudinal progression tracking is required, avoids dependence on a single "snapshot" measurement, and allows for improved signal quality through aggregation of EEG data collected in the home (an unsupervised environment).

Analyses are presented that quantify reported ease-of-use, and resultant levels of weekly adherence over a period of 3 months of unsupervised at-home use. The gamified cognitive tasks are evaluated for face-validity, by comparing key known behavioural effects with data gathered in the home, and examining effects of age that have been reported in the literature. Similarly the EEG data is examined at grand-average level to confirm that it replicates the main features (waveform morphology and timing, frequency content, scalp topography) of the neural signatures that the gamified tasks are designed to elicit.

\section{METHOD}

\section{Participants}

89 healthy adult volunteers (67 female), aged between 40 and 79 years (mean 58.78, s.d. 8.86) with a Montreal Cognitive Assessment (MoCA) score $\geq 24$ gave informed consent to take part in the procedures approved by Queen's University Belfast Ethics Committee. Recruitment channels included "Join 


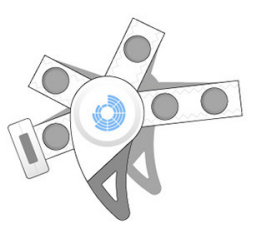

Headset

Raw EEG
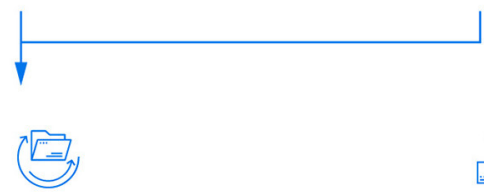

Data Upload

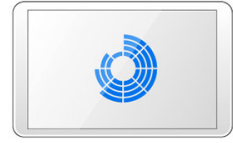

Tablet Based Tasks
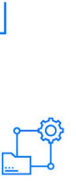

Data Preprocessing

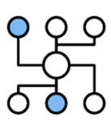

Other Data Streams

Fitness Tracker

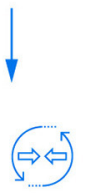

Feature Extraction and Generation

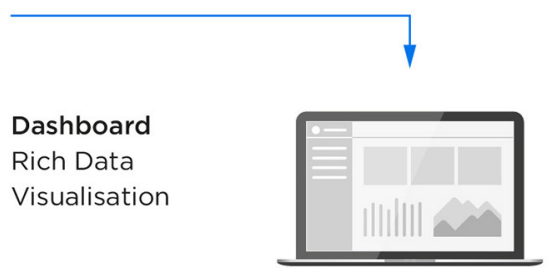

FIGURE 1 | Flow of EEG and behavioural data.

Dementia Research," local community groups and use of print media and social media.

\section{The Platform}

The platform was designed to enable frequent, objective sampling of brain-based markers of cognition inside and outside of the clinic/lab setting, using a dry sensor, wireless encephalography (EEG) headset that records brain activity, accompanied by gamified versions of cognitive tasks presented via a tablet-based app. Upon logging into the app, a stepwise tutorial guides the user through setup of the headset (covering placement on the head, positioning of the detachable mastoid sensors and feedback on sensor impedances) in preparation for recording data during the gamified tasks. Cloud-based secure methods are used for collection and automatic processing, as well as integration with other data streams (in this study participants wore a fitness tracker, the Withings Go) and web-based dashboards for monitoring and data visualisation on a daily, session-by-session basis (Figure 1).

\section{EEG}

The wireless EEG headset (Figure 2) consists of dry flexible $\mathrm{Ag} / \mathrm{AgCl}$ coated polymer sensors at 16 channels (O1, O2, P3, Pz, P4, Cz, FT7,FC3, FCz, FC4, FT8, Fz, AF7, AF8, FPz). The left and right mastoids are used for reference and driven-bias, with single-use, snap-on electrodes attached to wires extending from the headset. The electronics and sensors are mounted on flexible neoprene, and the stretchable structure incorporates anatomical landmarks in the form-fit of the headset to encourage consistent placement by users in line with the 10-20 sensor system. The analogue headset has high input impedance of $1 \mathrm{G} \Omega$, a configurable driven bias function for common-mode rejection, built-in impedance checking, and configurable gain and sampling rates. An onboard processor and Bluetooth module transmit $250 \mathrm{~Hz}$ EEG data to the tablet, from where it is transferred to a cloud server for storage and processing. EEG recording and behavioural events are timestamp synchronised to $\pm 2 \mathrm{~ms}$.

\section{Cognitive Tasks}

The gamified tasks (Figure 3) are based on well-known paradigms from experimental electrophysiology and cover a range of core cognitive functions. Cognitive/electrophysiological tasks were gamified with the aim of improving motivation, i.e., to enhance attentiveness during testing and to prevent boredom over repeated plays, while maintaining the core cognitive components of the original task. Feedback on gameplay performance was provided (e.g., points awarded for speed of responses where appropriate), along with personalised leaderboards to promote long-term adherence to the study schedule. Each daily session comprised a resting state plus two of the four other games (alternating between sessions). Participants also answered a daily health and lifestyle questionnaire to further contextualise the daily recordings. Daily sessions were designed to take $<30 \mathrm{~min}$ total time from start to finish.

\section{Two-Stimulus Visual Oddball}

This gamified version of the classic 2-stimulus visual oddball paradigm (58), presents target stimuli (aliens-requiring the 

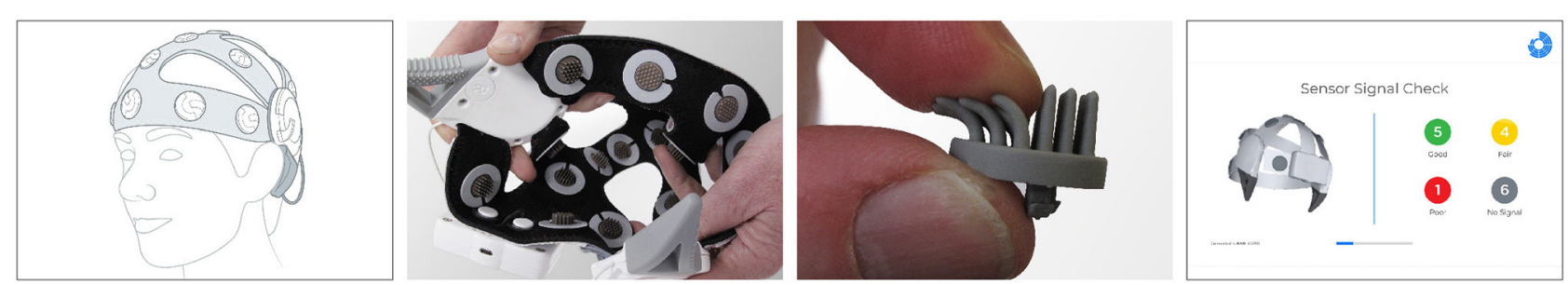

FIGURE 2 | Sixteen-channel wireless headset designed with pliable sensors and the sensor signal quality check.
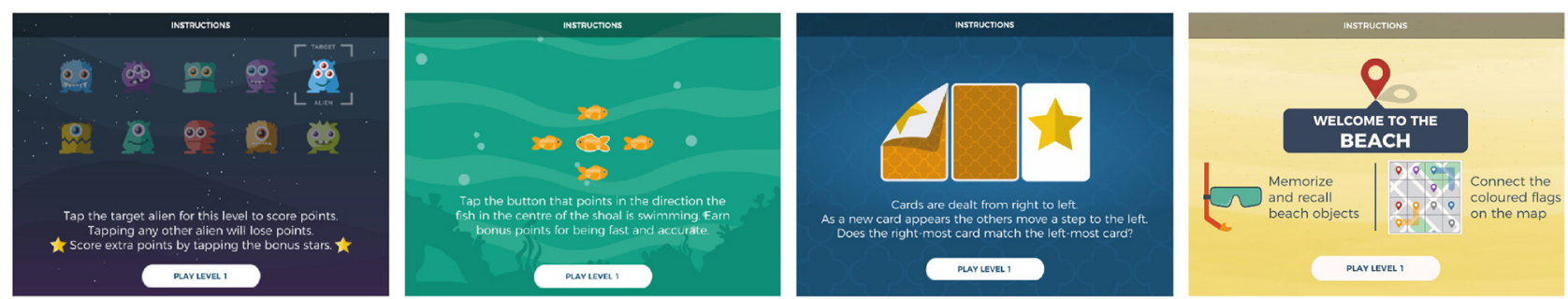

FIGURE 3 | Images of 2-stimulus visual oddball, flanker, n-back, and delayed match-to-sample gamified tasks.

participant to tap on the screen, $n=30$ ) and non-target stimuli (visually different aliens-requiring no response from the participant, $n=70$ ) across five levels of gameplay, as well as 15 "bonus" stars throughout the game (to enhance gameplay and not included for analysis). Behaviour (reaction time and response accuracy) and corresponding EEG correlates are indicative of neural dynamics of the decision-making process and the attention and working memory on which it relies (5961). Using EEG, a positive voltage deflection can be observed over the parietal cortex starting $\sim 300 \mathrm{~ms}$ following presentation of the stimulus, known as the P300 event-related potential (ERP). With advancing age, the amplitude of the P300 is known to decrease, and its latency known to increase (62-64).

\section{Flanker}

Inhibition and error awareness were probed using a gamified version of the Erikson Flanker task (65). Fish served as directional stimuli and were presented across five levels with a shoal of fish (flanking stimuli) appearing first, followed by the central (target) fish. The participant was asked to tap on the side of the screen corresponding to the direction of the central fish, ignoring the flanking fish (either congruent or incongruent stimuli, split evenly between the 150 trials), presenting a cognitive challenge reflected in behavioural responses (accuracy and reaction time) and EEG. The relevant EEG metric extracted from this task is the Error-related negativity (ERN)a negative voltage deflection observed on error trials most prominently over the fronto-central scalp, followed by a subsequent positive rebound in the signal (the Error Positivity, or Pe) (66). Previous studies have consistently reported a decrease in the negative amplitude of the ERN with progressing age (67).

\section{$N$-Back}

The visual $n$-back paradigm (68) taxes working memory and executive function with age-related differences in behavioural performance, according to recent meta-analysis (69). In the current study, this game had a continuous short-sequence memorisation of 4 different playing cards where the participant was asked whether the current card is a "match" or "nomatch" to the card seen 2 trials before. This 2-back paradigm consisted of 100 trials presented across two levels, with a 33\% match rate.

\section{Delayed Match-to-Sample}

A visual delayed match-to-sample task, this task targets recognition memory, a key cognitive function known to be affected by age (70), across 50 trials, presented in blocks of 5 , with $50 \%$ overall match rate (71). Each level is set in a specific location (beach, jungle, etc) where the user is presented with a variety of objects which must be encoded into memory to be retrieved after a brief (10-s) distractor game which involves connecting dots. Points are earned by identifying previously presented items at retrieval and rejecting unseen items.

\section{Resting State}

In this passive task (72) participants selected a relaxing scene (forest, park or beach) for $1 \mathrm{~min}$ of restful eyes open followed by $1 \mathrm{~min}$ eyes closed. This task elicits resting electrocortical activity and seeks to produce an increase in the neural oscillatory power of the alpha frequency band $(7-13 \mathrm{~Hz})$ when eyes are closed relative to eyes open, a physiological measure sensitive to a range of neurocognitive and psychiatric disorders, ageing, as well as sleep quality and caffeine intake (22, 73-75). 


\section{Procedure}

Participants attended two in-lab sessions, at baseline and following 12 weeks of at-home use of the platform.

\section{Lab Sessions}

Lab sessions consisted of neuropsychological testing followed by in-lab use of the platform. Neuropsychological assessment was carried out for screening and to facilitate potential longitudinal follow-up and/or comparison with other datasets, and is not analysed in this paper. The MoCA (76) was selected as a screening tool using a cut-off of $\geq 24$ to be representative of normal cognitive function, in line with findings reported in the Irish older adult general population $(77,78)$. Participants then completed tasks from the Cambridge Neuropsychological Test Automated Battery (CANTAB) covering multiple domains including psychomotor skills, executive function, memory and attention domains before completing a session with the platform. Participants provided ratings of the usability of the platform at baseline, 6 and 12 weeks into the study on the System Usability Scale (SUS), a 10-item industry standard questionnaire designed specifically to assess use of technology (79).

\section{Home Sessions}

Participants were asked to use the platform as described in section The Platform, at home, over the course of 12 weeks. These sessions were $\sim 25-30 \mathrm{~min}$ and participants were asked to contribute 5 sessions per week (one session per day, days unspecified for participant convenience). Throughout the 12week period, participants wore a fitness tracker to monitor their step count and sleep, and answered questions about daily wellbeing and lifestyle habits (not analysed in the current paper).

\section{Analysis}

To measure usability of the platform across age groups and feasibility of extracting features reflecting cognitive ageing, participants were assigned to three groups for analysis: those aged 40-54 $(n=26)$, 55-66 $(n=35)$, and 67-79 $(n=17)$ years. Usability measures used for analysis were adherence and participant-reported SUS scores, as well as technical measures of signal reliability. To investigate feasibility and explore effects of cognitive ageing, behavioural and EEG metrics were extracted across age groups. Additionally, event-related potential waveforms were plotted for comparison based on single gameplay median epoch, single-participant averaged epochs and whole-sample grand averaged epochs. Validity of the approach can be established by confirming that behavioural and neural patterns observable in the literature (e.g., differences in timing between congruent and incongruent trials; the waveform and scalp topography of ERP components) are seen in the data recorded unsupervised in the home, and that age-related changes in these variables reflect the published consensus. Ninety five percentage confidence intervals are reported throughout using the upper and lower bounds.

\section{Behavioural Analysis}

Measures of accuracy and speed of response were extracted from the cognitive games played using the platform (2stimulus oddball, flanker, n-back and delayed match-to-sample) to establish face validity against that which the literature leads us to expect. For this analysis, we averaged different behavioural measures across game-plays. To investigate reaction times, we chose the median reaction time per game-play, taking the median-average per participant to calculate age group mean comparisons and sample means. To compare rates of accuracy, we calculated percentage accuracy per game-play. We produced a mean accuracy rate per participant for age group and sample mean comparisons. Additionally, we calculated confidence intervals as an indication of variance. To visualise age group differences across game plays, the log-transformed game-play number was used as an explanatory variable of the different behavioural metrics per group in a linear model and a 95\% confidence interval was calculated using 1,000 bootstrapping resamples.

\section{EEG Analysis}

The processing pipeline consists of filtering from 0.25 to $40 \mathrm{~Hz}$, customised artefact removal, epoch extraction and baseline removal. Metric-based methods for removing invalid ERPs and PSDs were applied to outputs. Two event-related potential (ERP) components, the P300 (a positive-going waveform which peaks $>300 \mathrm{~ms}$ after the presentation of an attended stimulus, associated with decision-making) and the ErrorRelated Negativity (a negative-going, response-locked waveform associated with error-awareness) were computed as the smoothed pointwise median of epochs within each session. Power spectral density (PSD) was computed using a 1,024 point Fast Fourier Transform (FFT) with Welch's method of averaging (using a 256 sample window) on the resting-state eyes-open and eyesclosed data. For this analysis, time-series data was converted to average reference to remove lateralised effects of the original single-mastoid reference. Mean and 95\% confidence intervals were computed across all sessions from participants within each age group.

\section{RESULTS}

\section{Usability}

Of the 89 healthy adult participants that enrolled in the study $(67$ female, mean age $=58.78$, mean MoCA score $=27.12), 11$ participants withdrew and 78 (61 female) completed the study (mean age $=58.99$ mean MoCA score $=27.06$ ), yielding an attrition rate of $12.40 \%$. Data from those who withdrew was excluded from the following analyses reported.

Reasons for withdrawal cited were work/caring/other commitments $(n=3)$ and/or illness/health-related issues $(n=$ 6). Two participants cited both health and caring commitments. One participant mentioned a faulty headset as an additional factor in the decision to withdraw; this participant's headset had required repair. Four participants did not give any reason. The mean number of sessions contributed by participants who 


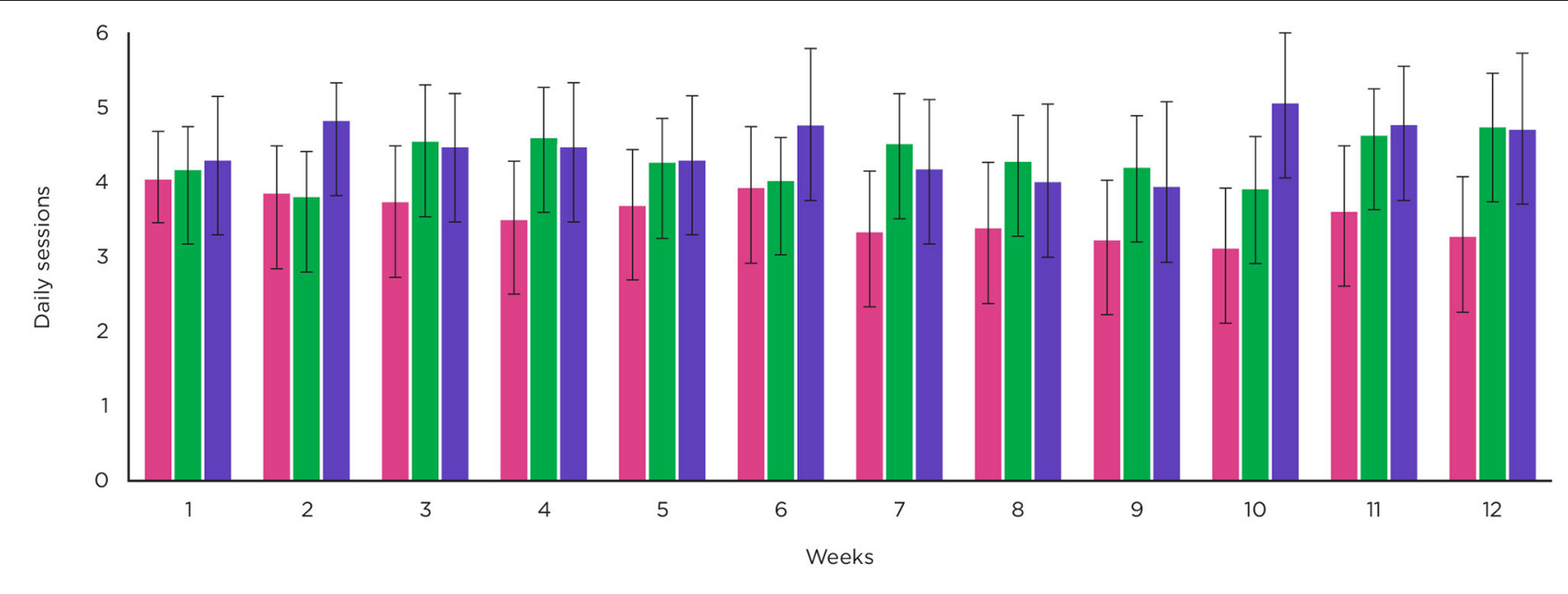

40-54 55-66

$67-79$

FIGURE 4 | Weekly adherence. Mean number of sessions per week across all participants and by age group. Error bars show upper and lower $95 \%$ confidence intervals.

TABLE 1 | System usability scale scores by age group at baseline, 6 and 12 weeks.

\begin{tabular}{|c|c|c|c|c|c|c|c|c|c|}
\hline & \multicolumn{3}{|c|}{ 40-54 years } & \multicolumn{3}{|c|}{$55-66$ years } & \multicolumn{3}{|c|}{$67-79$ years } \\
\hline & Mean & $95 \% \mathrm{Cl}$ & $n$ & Mean & $95 \% \mathrm{Cl}$ & $n$ & Mean & $95 \% \mathrm{Cl}$ & $n$ \\
\hline Baseline & 81.35 & \pm 5.99 & 26 & 77.94 & \pm 4.60 & 34 & 66.62 & \pm 9.01 & 17 \\
\hline 6 weeks & 81.56 & \pm 5.81 & 24 & 85.44 & \pm 3.69 & 34 & 72.81 & \pm 7.08 & 16 \\
\hline 12 weeks & 80.50 & \pm 6.04 & 25 & 81.50 & \pm 4.62 & 35 & 68.38 & \pm 8.05 & 17 \\
\hline
\end{tabular}

withdrew was 16.82 [8.41-25.23], ranging from 1 (completed inlab) to 45 sessions. The mean duration of at-home involvement by those who withdrew was 5.55 weeks [3.22-7.88].

Figure 4 shows the rate of weekly adherence for those who completed the study $(n=78)$, including a breakdown of weekly adherence by age group [ $40-54$ years $(n=26), 55-66$ years $(n$ $=35)$ and 67-79 years $(n=17)]$. For those who completed, mean number of sessions contributed per week was 4.10 [3.974.23 ], out of a target of 5 per week and the mean total number of sessions contributed per participant was 49.14 [46.54-51.74]. By age group, mean number of sessions per week was 3.56 [3.333.78] for those aged 40-54, 4.31 [4.12-4.50] for those aged 55-66 and 4.48 [4.22-4.74] for those aged 67-79 years.

Participants were asked to evaluate usability via the System Usability Scale (SUS) at 3 timepoints. Mean SUS scores were 76.59 [72.94-80.24] at baseline, 81.45 [78.33-84.57] at 6 weeks and 78.28 [74.74-81.81] at 12 weeks (see Table 1). It is worth noting that the mean SUS score at baseline from those who subsequently withdrew was 75.23 [64.42-86.04] and of those who were still enrolled at 6 weeks, mean SUS score was 74.64 [62.6286.67].

Ability to use the system to record usable EEG in the athome setting, reported in Figure 5, was considered by measuring the percentage of time that individual sensors were connected to the scalp (i.e., recording non-saturated data) for the different age groups. Three thousand six hundred three sessions were successfully uploaded to the cloud server. Of these, $95.81 \%(3,452$ sessions) contained portions of EEG data that could be used for analysis, even though certain sections of that session, or certain sensors, may be very noisy. One hundred and fifty-one sessions were rejected in their entirety, due to saturated data sections, high variance sections or gaps. By comparison, the behavioural data, where $99.03 \%$ (3,568 sessions) contained a complete set of response measures for at least one of the two games assigned per session. There were 116 sessions for which behavioural data, but not EEG data, was suitable for analysis.

\section{Behaviour}

To establish face validity of the gamified behavioural tasks, key metrics from each game were extracted to evaluate against what would be expected from traditional lab paradigms described in the literature. The temporal development of several illustrative metrics, stratified by age-group, is displayed in Figure 6.

\section{Two-Stimulus Oddball Game}

Similar to lab versions of simple decision-making task which do not challenge the accuracy of responses, the gamified version demonstrated high accuracy, mean 97.71 [97.08-98.35]\%. Age 


\section{0-54}

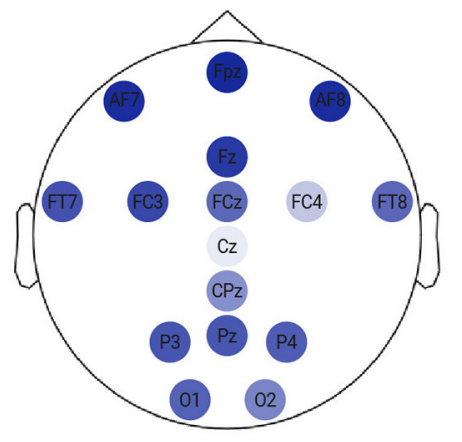

$55-66$

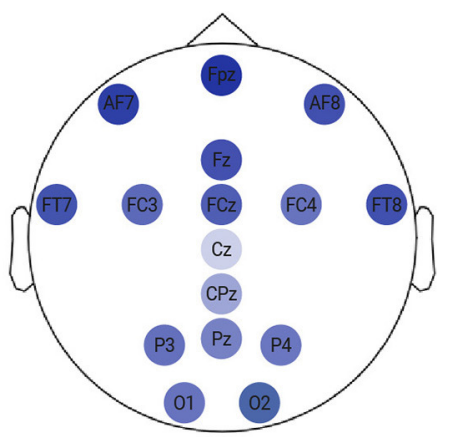

$67-79$

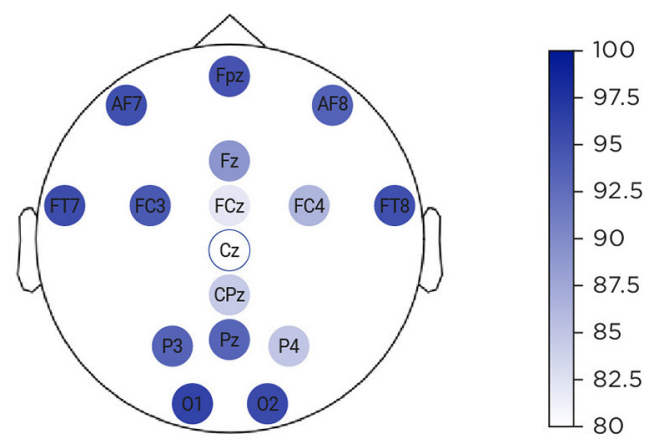

FIGURE $\mathbf{5}$ | Percentage of time each of 16 channels recorded non-saturated data, shown across age groups.

A

Oddball

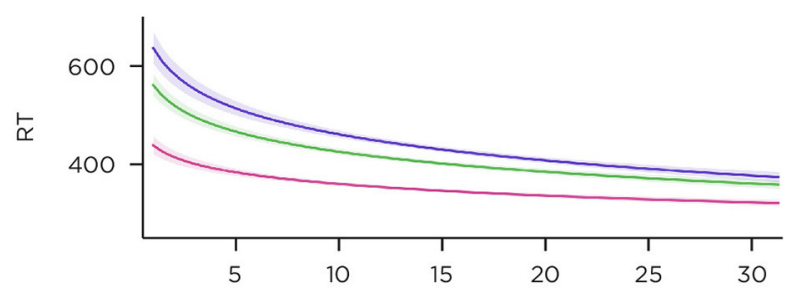

Game plays

C

N-back

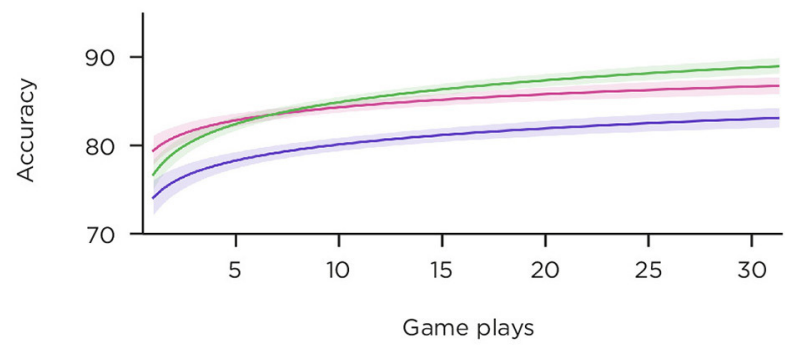

B Flanker

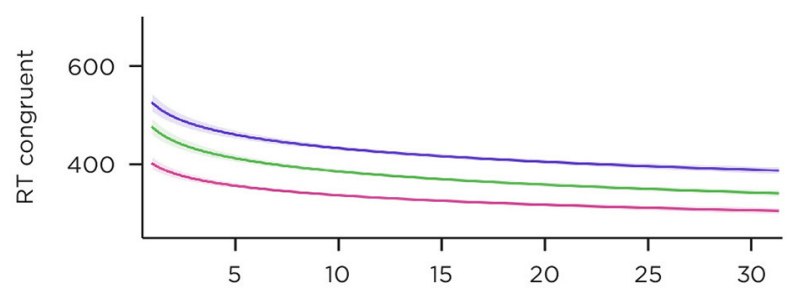

Game plays

D Delayed match-to-sample

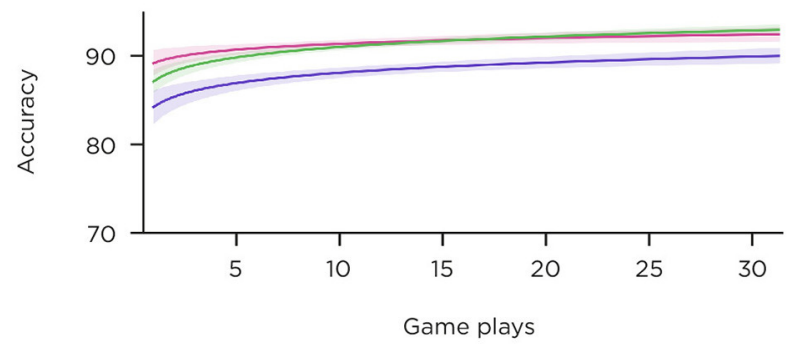

$67-79$

FIGURE 6 | Behavioural responses to gamified cognitive tasks over 12 weeks across age group. Shading indicates 95\% confidence interval. (A) median correct RTs to targets in 2-stimulus oddball task; (B) median correct RTs to congruent trials in flanker task; (C) percentage accuracy, all trials, n-back task; (D) percentage accuracy, all trials, delayed match-to-sample task.

group means were 98.7 [98.32-99.08]\% for $40-54$ years, 98.05 [97.16-98.95]\% for 55-66 years, and 95.5 [93.62-97.39]\% for 67-79 years. As the game rewards speed of response (in its scoring procedure), and due to learning/strategizing effects, we expected reaction time (RT) to improve with repeated gameplays. Figure 6A shows the temporal trend of speed of response over consecutive sessions, and clear separation of the three age bands is visible. Reaction time per group, averaged over all sessions, was
366.76 [352.68-380.84] milliseconds ( $\mathrm{ms}$ ) for 40-54 years, 414.85 [393.17-436.54] $\mathrm{ms}$ for 55-66 years and 449.58 [423.45-475.70] ms for 67-79 years.

\section{Flanker Game}

This task is time-restricted, and encourages the player to make a trade-off between speed and accuracy of response (as erroneous response trials are those that yield the key EEG 
metric). Incongruent trials require inhibition and possible motorreplanning relative to congruent trials, and this is seen in an inhibition cost of 62.16 [56.62-67.7] $\mathrm{ms}$. The inhibition cost per age group was 55.87 [48.28-63.45] $\mathrm{ms}$ for $40-54$ years, 64.67 [56.0-73.34] $\mathrm{ms}$ for 55-66 years and 66.89 [52.99-80.8] $\mathrm{ms}$ for 67-79 years.

Incongruent trials induced many more errors [8.45 (7.069.84)] than congruent trials [2.02 (1.66-2.68)]. Looking at the temporal development of the congruent condition reaction times alone (Figure 6B), a pattern of learning from session to session, and separation of age bands, is visible.

\section{N-Back Game}

This game requires cycling of information in and out of shortterm memory. RTs were slower for non-match [1,075.83 (990.771,160.9) $\mathrm{ms}$ ] than match trials [919.56 (857.76-981.36) $\mathrm{ms}$ ], however accuracy rates were higher for non-match [87.71 (86.41$89.01) \%]$ vs. match trials [74.76 (71.91-77.60)\%]. Accuracy rate was 76.49 [72.96-80.02]\% for $40-54$ years, 75.56 [70.57-80.55]\% for $55-66$ years and $70.46[64.6-76.32] \%$ for $67-79$ years on match trials and 87.51 [85.73-89.29]\% for $40-54$ years, 89.29 [87.41-91.16]\% for 55-66 years and 84.77 [81.47-88.08]\% for 6779 years on non-match trials. Figure $6 \mathrm{C}$ shows accuracy rates on all trials, by age group, across repeated game-plays.

\section{Delayed Match-to-Sample Game}

This is not a speed challenge task, however, RTs to match trials were faster than non-match trials 886.99 [847.27-926.71] ms vs. $1,060.31$ [1,013.4-1,107.22] ms, a pattern reflected in RTs by age group: 796.27 [754.02-838.52] ms, 890.05 [840.75-939.35] ms and $1,027.89$ [914.95-1,140.83] ms for match trials compared to 944.11 [898.82-989.41] ms, $1,079.58[1,007.6-1,151.56] \mathrm{ms}$ and $1,208.17$ [1,102.96-1,313.39] ms for non-match trials, for $40-54,55-66$, and 67-79 years. Memory performance is known to decrease with age, and divergence can be seen in Figure 6D for the oldest age-band, though again not between the younger and middle bands. Separate examination of the accuracy for match and non-match trials showed that this difference in performance was primarily driven by the non-match trials. Over the sample, accuracy was 93.16 [92.04-94.28] for match vs. 81.82 [79.35-84.30] for non-match trials, while accuracy rates across the age groups showed more difference for non-match compared to match trials: 85.67 [82.61-88.72], 80.98 [76.7285.24], and 77.38 [72.51-82.24], compared to 93.85 [92.4195.28], 93.12[91.24-94.99], and 92.12 [89.44-94.81] for nonmatch and match trials, respectively, for the age groups 40-54, 55-66, and 67-79 years. These results suggest that the non-match trials acted as effective lures.

\section{EEG}

For the resting-state task, power spectral density (PSD) was plotted at occipital sites to explore the effectiveness of the platform to measure change in alpha power between the eyesopen and eyes-closed conditions of resting-state task, across the three different age bands (Figure 7). Data from all 78 participants was included in the analysis. The number of sessions per comparison at electrode site $\mathrm{O} 1$ for eyes-open/eyes-closed were 904 for 40-54 years, 1,511 for 55-66 years, and 791 for 67-79 years. For electrode site $\mathrm{O} 2$, number of sessions were 903 (40-54 years), 1,513 (55-66 years) and 792 (67-79 years). The eyes-open data clearly shows the expected $1 / \mathrm{f}$ pattern of signal power falling with increasing frequency, and an alpha band peak around $10 \mathrm{~Hz}$. As expected, the alpha peak amplitude is increased in the eyes-closed condition, as well as in the lower beta band $(15-20 \mathrm{~Hz})$. Figure $7 \mathrm{~A}$ displays the effect of age group on absolute band power. There is a clear monotonic decrease in power with age in the difference condition with the largest eyesopen/eyes-closed difference for those aged 40-54 and the smallest difference for those aged 67-79 in the alpha and lower beta range. Furthermore, it can be seen that the average peak alpha frequency is highest for younger participants, and lowest for older participants. No consistent pattern is apparent in alpha power for the eyes-open and eyes-closed conditions alone, although there are clear distinctions between groups in the gamma range (30$35 \mathrm{~Hz}$ ). This may indicate a difference in noise floor between the age groups. We applied a suitable normalisation by taking the relative power on this analysis (80). Relative power is shown in Figure $\mathbf{7 B}$, again demonstrating a stratified pattern of age group on alpha power and peak frequency, most evident in the graph of the eyes-closed condition. It is noticeable that there is more fluctuation in the higher frequencies for the oldest age group (67-79 year olds).

Evoked and event-related potentials elicited in the gamified 2-stimulus oddball and flanker tasks were also extracted at a single-session, single-participant and grand average level (shown in Figures 8, 9). Figure 8C illustrates the grand average ERP for target trials on the 2-stimulus oddball, at the centro-parietal location $\mathrm{CPz}$, where the $\mathrm{P} 300$ is centred. This is a robust average over multiple sessions contributed by 77 participants, time-locked to the presentation of the stimulus (data from one participant, $n=26$ sessions, did not meet quality thresholds for inclusion at this channel). Interpolated topographies (Figure 8D) across all 16 channels at ERP peaks are shown at 0, 200 and $420 \mathrm{~ms}$ post-stimulus onset. The principal waveform features of a P300 ERP are visible in the early sensory processing components ( $\sim-250 \mathrm{~ms}$ with an occipital focus) and the P300 component ( $\sim 300-500 \mathrm{~ms}$, with a centro-parietal focus). A strong readiness potential can also be seen before stimulus presentation $(-500-$ $0 \mathrm{~ms}$ ). The other two panels show the median stimulus-locked epoch from 29 correctly identified target trials from a single game-play session (Figure 8A), and the median-average across 18 out of a total of 21 game-play sessions (3 did not meet quality thresholds), contributed by a participant aged 44 years (Figure 8B). Figure 8E demonstrates examples of successful session-level ERPs evoked during a single game-play session, representing 6 users across the different age groups in the study (2 participants from each age group). Unsuccessful sessions yield waveforms that show a discernible ERP overlaid with noise, flatline signals (e.g., due to an unconnected sensor), or noise of various heterogenous types.

Figure 9C illustrates the grand average difference ERP for error trials on the flanker task, at the central $\mathrm{Cz}$ location, where the ERN is observed (total 1,004 sessions). This is a robust average over multiple sessions contributed by 76 
A 01
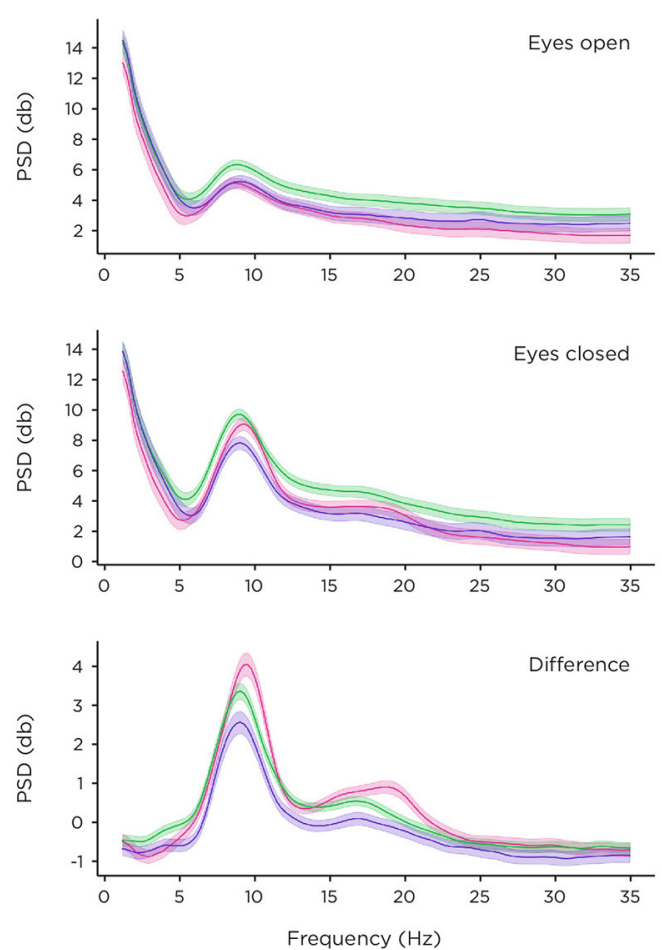

B 01
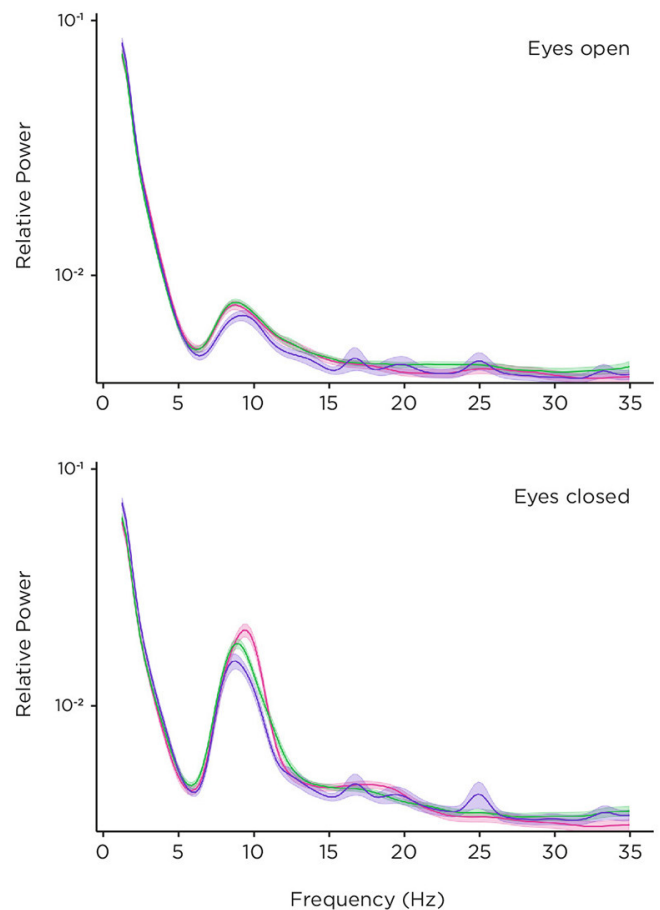
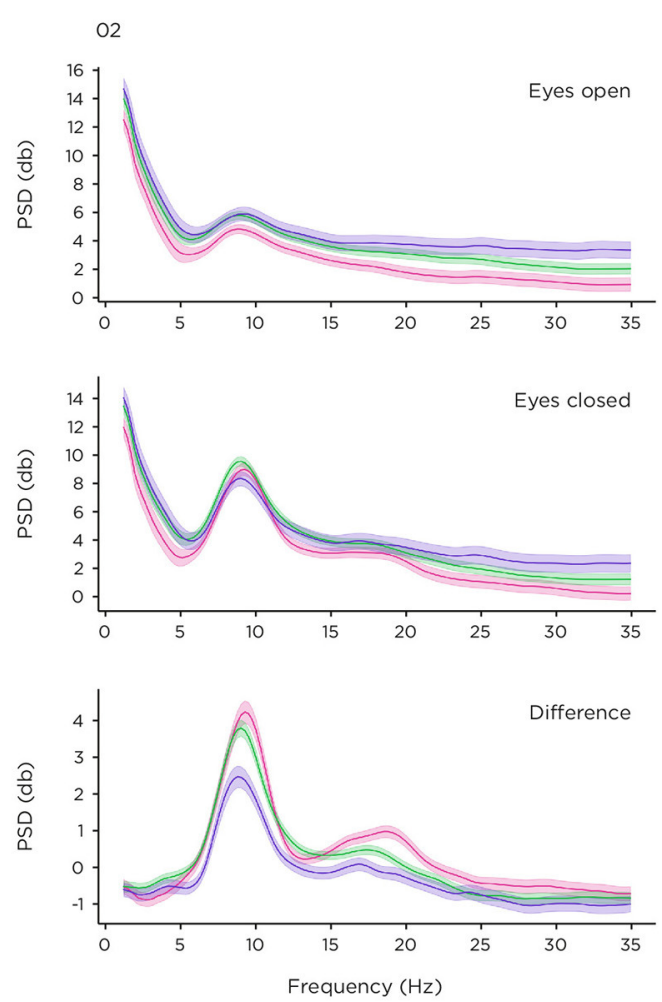

02
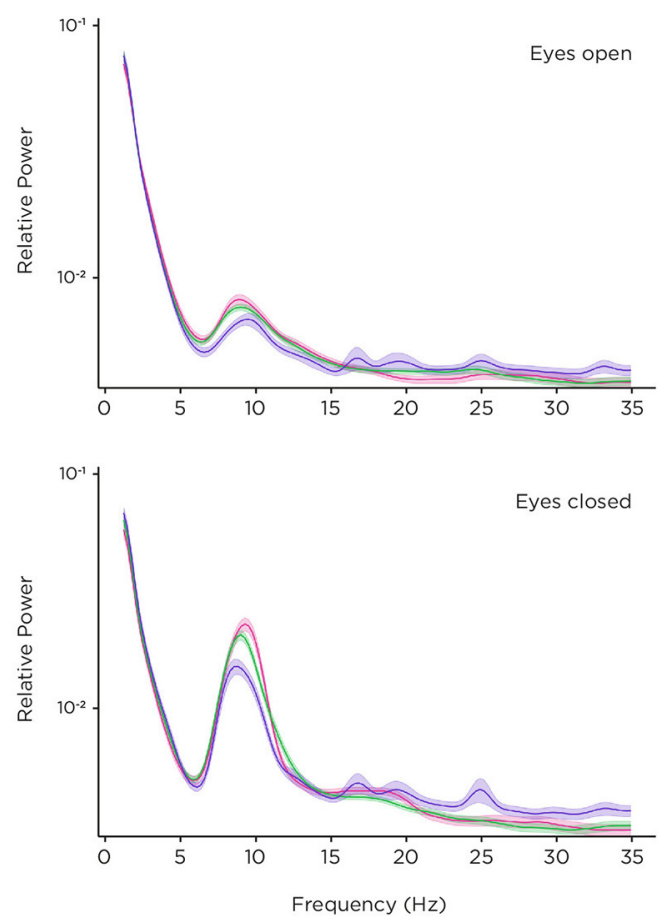

40-54

$55-66$

67-79

FIGURE 7 | Resting state task. (A) power spectral density (PSD) in decibels (dB) at O1 and O2 by age group in eyes-open and eyes-closed conditions, and the difference condition; (B) relative power at $\mathrm{O} 1$ and $\mathrm{O} 2$ by age group in eyes-open and eyes-closed conditions with logarithmic scaling for display only. 


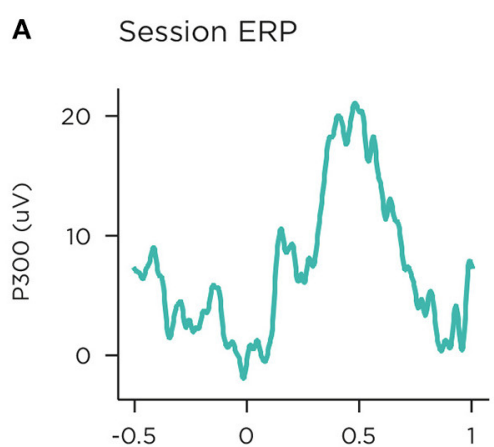

Time from stimulus onset (sec)
B

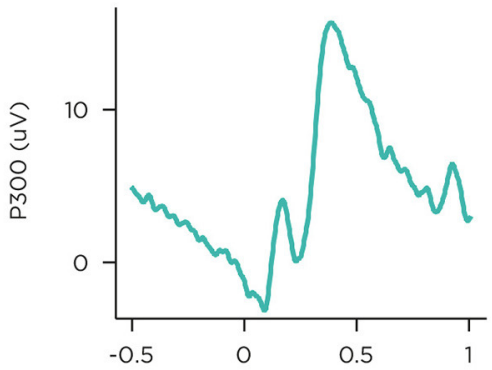

Time from stimulus onset (sec) c Grand average ERP

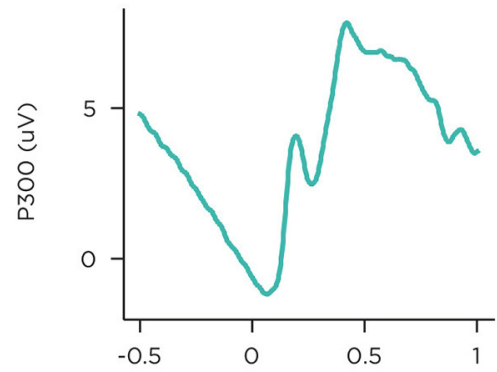

Time from stimulus onset (sec)

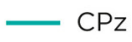

D Grand average topography

Time point: 0.00

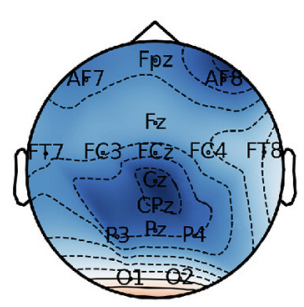

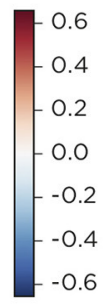

Time point: 0.20

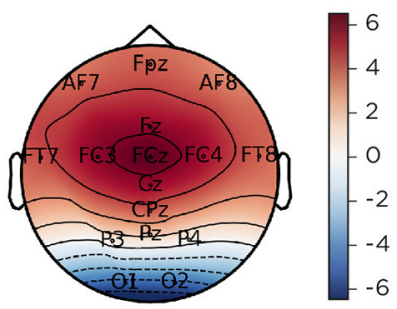

Time point: 0.42

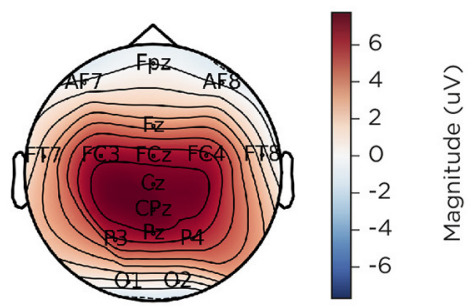

E

Single Session ERPs

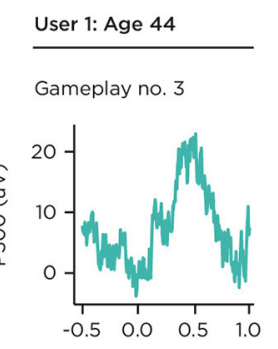

Gameplay no. 12

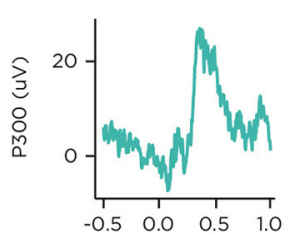

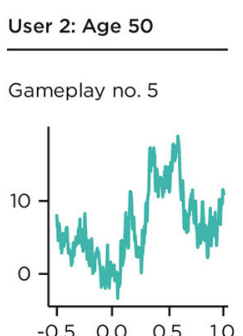

Gameplay no. 17

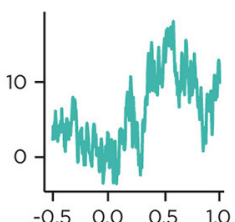

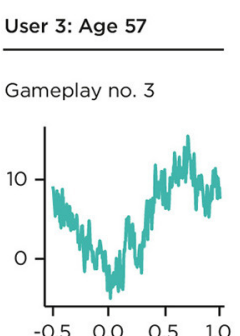

Gameplay no. 22

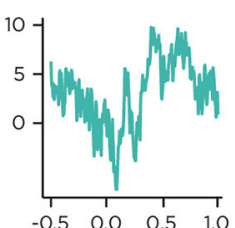

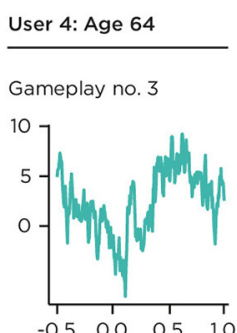

Gameplay no. 16

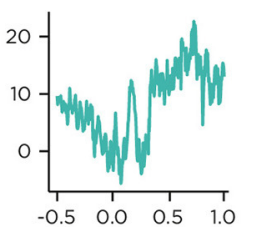

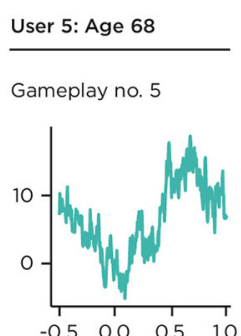

Gameplay no. 13

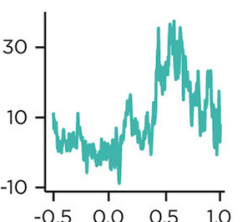

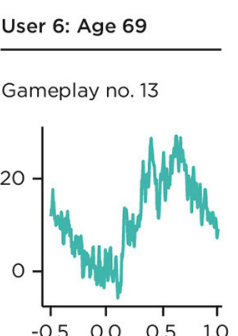

Gameplay no. 28

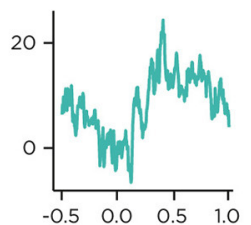

FIGURE 8 | P300. (A) single-session median; (B) single-participant mean; (C) grand mean; (D) grand mean topographies selected at ERP peak timepoints; (E) examples of single-session median ERPs successfully recorded from game plays from 6 different participants (2 participants per age group). 


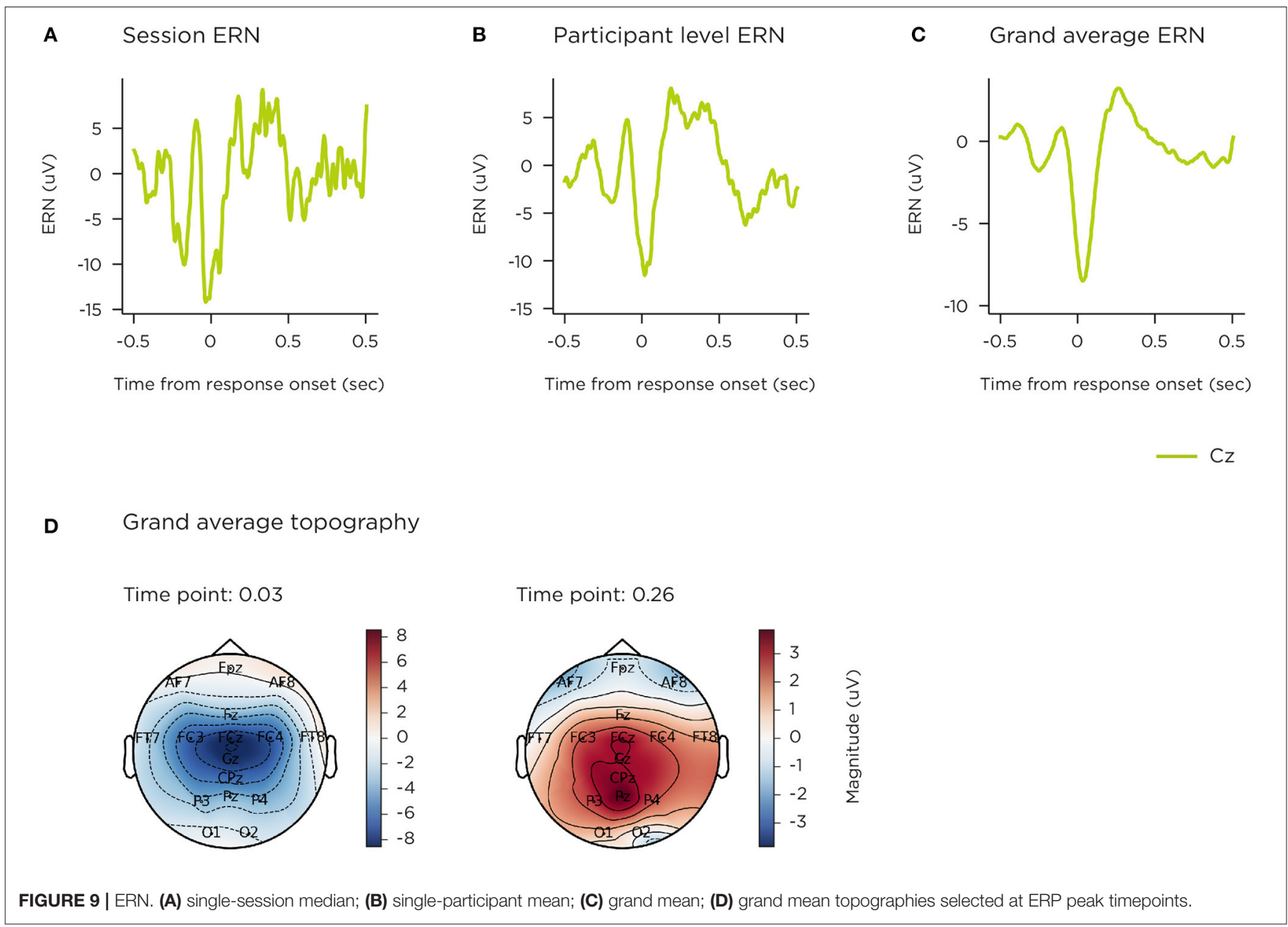

participants, time-locked to touch-response (single-channel data was excluded from 2 participants, who contributed 6 and 8 sessions). Grand average topography (Figure 9D) across all 16 channels at ERP peaks are shown at 30 and $260 \mathrm{~ms}$ poststimulus onset. The event-related negativity (ERN) waveform is clearly represented (peaking at $\sim 50 \mathrm{~ms}$ ), with a central focus, as is the error positivity $(\mathrm{Pe})$ with a centro-parietal focus (peak $\sim 250 \mathrm{~ms}$ ). Figure 9A shows the corresponding median responselocked epoch across 12 error trials following a single game-play session, contributed by a participant aged 52 years. Figure 9B displays that participant's median-average across 14 out of 16 game-play sessions.

The P300 and ERN components were also compared by age group. Figure 10A shows grand-averaged epochs per age group on single channel $\mathrm{CPz}$ for the stimulus-locked ERP from the visual oddball, and Figure 10B shows these at $\mathrm{Cz}$ for the response-locked ERP of the flanker task. The number of participants and sessions per comparison at electrode site $\mathrm{CPz}$ were 26 and 397 for 40-54 years; 34 and 515 for 55-66 years; 17 and 240 for 67-79 years. For electrode site $\mathrm{Cz}$, number of participants and sessions were 23 and 339 (40-54 years); 35 and 473 (55-66 years); 17 and 182 (67-79 years). The impact of signal variability from individual sessions (both noise, and genuine inter-individual differences) is quantified in the $95 \%$ confidence intervals illustrated.

The P300 shows early differences in latency in sensory processing, and separation in amplitude among the groups, where disruption increases with age. In the Flanker task ERP, the early ERN component is attenuated in both older groups, relative to the youngest group, and the later Pe component is reduced for the oldest group.

\section{DISCUSSION}

\section{Usability}

This proof-of-concept paper reports findings from the first time that this novel EEG platform was deployed in-field. After a single training session, participants, including older adults up to the age of 79 years, were able to use the technology at home to successfully perform EEG and behavioural recordings without the supervision of trained technicians. This study yielded 3,603 uploaded sessions, $>95 \%$ of which contained usable data (i.e., EEG and behavioural metrics could be extracted from the submitted data), providing encouraging evidence supporting the feasibility of this technological approach to cognitive neuroscience research. 


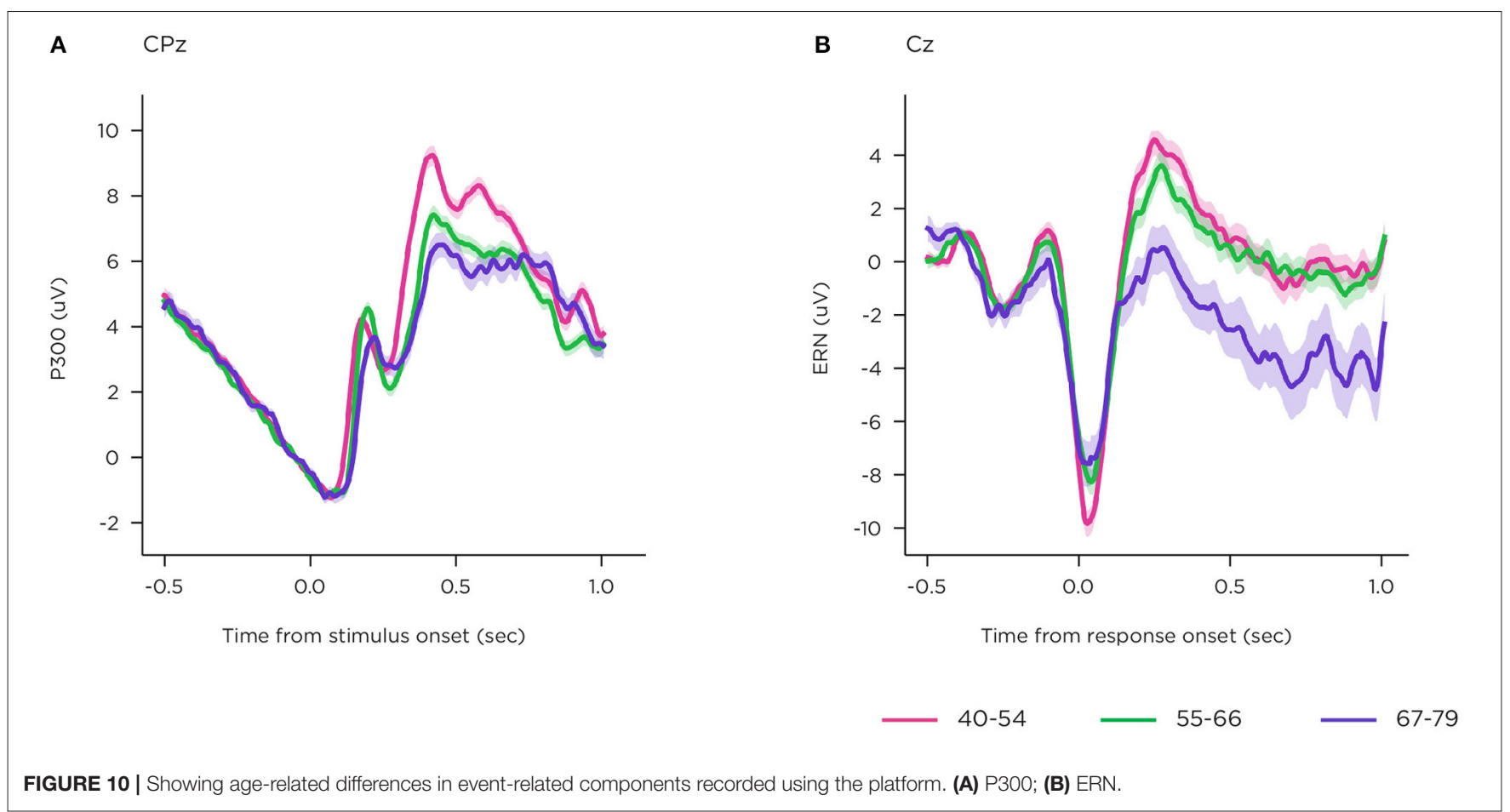

Users were asked to trial and evaluate this new system for monitoring brain health at home and to contribute five 30min recording sessions per week, which was a considerable effort given that no extrinsic incentives or disincentives were applied to promote adherence to this schedule. Adherence to this schedule was remarkably high, relative to other reports of in-home monitoring devices in older populations over similar time courses $[\sim 55 \%(81,82)]$. For the current study, attrition was low (12.4\%) and the average contribution was $>4$ sessions per week ( $>80 \%$ adherence to schedule). Older adults had the highest rates of adherence, indicating that age was no impediment to using the system regularly. A high level of adherence was maintained throughout the 3-month period without substantial decline in the latter weeks of participation, testament to both the power of gamification and usability of the system motivating and facilitating repeated play, and the level of commitment from the study participants. Maintaining adherence in unsupervised environments is challenging and may be particularly so for psychiatric populations (83), however widespread evidence from other diseases, where there has been a broad uptake in new technologies, indicates that patient-centric digital monitoring provides more objective, frequent tracking with clear healthcare benefits (84-86) and have been shown to lead to better compliance relative to paper based assessments $(86,87)$.

Reported usability was somewhat lower for the oldest ageband, although it is worth noting that their lowest average score still falls within the range between "ok" and "good" (88). Contrary to our expectations, this did not result in reduced adherence, suggesting that many challenges of manual dexterity or familiarity with digital technologies had been successfully mitigated during the initial user-focused design process. However, signal reliability measures indicated that the oldest age band experienced the greatest difficulty in obtaining good sensor connectivity, particularly around the midline sensors $(\mathrm{Cz})$ located at the top of the head. Younger participants achieved slightly better connectivity at $\mathrm{Cz}$ but also better connectivity on adjacent sensors. Head shape is variable at the crown, meaning that generic headset sizing options are not always optimal. That location may also require additional manual dexterity and adjustment, which is more difficult for older populations. In the light of these findings from the first deployment of this technology in-field, subsequent incremental improvements to the headset, app and enrolment training procedures have been deployed which have resulted in superior sensor connectivity and data quality $(89,90)$.

In addition to investigating the overall usability of the platform, empirical data collected in this study was used to assess the potential of collecting scientifically valid neurocognitive data from remote, fully autonomous participants.

\section{Behaviour}

All gamified cognitive tasks exhibited some degree of a learning effect. Reaction times generally decreased rapidly over the first five sessions of a given task (see Figure 6). This likely reflects the development of task-specific perceptual-motor skill, rather than a change in the underlying cognitive function probed by the task (i.e., "brain training"). Time spent developing task strategies, and learning the layout of the task environment, is likely to have enabled more effective allocation of visual attention and therefore faster responding (91). Age-related effects on speed of response were generally preserved throughout this learning phase and 
into asymptote, with the oldest participants consistently making their responses more slowly than other age groups, consistent with the literature. Regarding accuracy over time, participants on average improved very slowly and consistently on the n-back task throughout the study, as expected since n-back variants are typically included with brain training suites due to their inherent learnability (92). Participants, regardless of age band, demonstrated less of a learning effect in the visual delayed match-to-sample task, potentially reflecting the simplicity of this basic old/new matching task for healthy adults however again, the oldest participants scored lowest on this task throughout the study, consistent with age-related decline in memory performance. These learning curves themselves (Figure 6), enabled through the ability to collect multiple assessments over time, may be a rich source of data and potentially informative measures of underlying cognitive function (93), with recent research showing that rate of learning, in the context of a cognitive task conducted over multiple days, can differentiate groups by age (94) and neuropathology (95).

\section{EEG}

EEG signals described in this paper (resting-state spectral activity and the P300 and ERN ERPs) demonstrate morphology consistent with those elicited by non-gamified, laboratory paradigms described in the literature. Furthermore, grand average visualisations of P300 and ERN ERPs across age bands replicate classic electrophysiological patterns of agerelated change.

The study design included repeated use to permit aggregation of EEG data collected in the home, as a means of improving reliability and signal to noise ratio. The focus in this paper is on group level grand-average analyses, common in cognitive neuroscience literature. Although, as can be seen in the data presented in this paper, it is feasible to obtain cognitive ERP components from users (across different age groups) based on single, home-based sessions. As might be expected, not all sessions were available for analysis with factors such as saturated signal or high variance rendering the data unusable. However, over $95 \%$ of sessions contained EEG from which at least a portion of the data was usable, even though certain sections of that session, or certain sensors, may have been noisy. In order to support participants to achieve good signal quality, the system included a sensor signal check step at the beginning of every session to give feedback on impedance levels to encourage selfadjustment for a good connection.

EEG devices that offer miniaturisation of the EEG amplifier, use of Bluetooth technology to transmit EEG data, precise stimulus event-marking, and a choice of wet or dry sensor set-ups, have been extensively evaluated in the literature [e.g., (54, 96-99)]. These demonstrate reduced set-up times and greater portability while generally maintaining good signal-tonoise ratio [e.g., (52, 53, 100, 101); but see Duvinage et al. (102), Maskeliunas et al. (103)]. However, the authors are not aware of reports of any other mobile EEG system for which repeated ERP data collection has been demonstrated in participants' home environment without a researcher present, as was the case in this study.
The P300 elicited from the 2-stimulus oddball task exhibited reduced amplitude and latency for the older age groups, consistent with previous studies (62-64). Whilst the underlying mechanisms are yet not fully elucidated, recent evidence points toward the P300 reflecting the accumulation of information leading to a decision (60), the ability to do this effectively being impaired by ageing and cognitive decline (104). ERP components evoked from the Flanker task also demonstrated sensitivity to ageing with a smaller ERN for the older age groups and a weak Pe for the oldest age band, reproducing known effects in the literature, reflecting a general weakening of the processes underpinning cognitive control in ageing populations $(67,105)$. Resting state EEG PSD demonstrated alpha band increase in the eyes closed condition relative to eyes open as expected. In the absolute power analyses differences in noise levels were observed. Grummet et al. (106) discusses variability in noise floor in dry EEG, which in this case may potentially be driven by factors such as systematic variation in the use of the headset, and age-related changes in skin condition (107). However, having controlled for differences in noise floor levels, we observed alpha band power and peak frequency stratification across that age groups that align with the effects of ageing on brain activity during resting state typically reported in the literature $(74,108,109)$.

\section{CONCLUSION}

In this paper we have described the first large scale field trial of a new suite of tools to collect clinically relevant domainspecific markers of brain function and cognitive performance unsupervised in the home. Human-factors feasibility was demonstrated by high reported usability, low levels of withdrawal, and adherence of $>80 \%$ over a 5-day-per-week, 3-month long, uncompensated participation. Newly gamified versions of established tasks were trialled and were successful in replicating key aspects of behaviour from their lab-based counterparts. Widespread learning effects were observed, as would be expected on repeated plays, but age-related differences were preserved over many weeks of repeated play. Grand average EEG data from the resting state, visual oddball and flanker tasks all illustrated core features of frequency content, waveform morphology and timing, and scalp topographies to confirm that they faithfully replicate the lab-based tasks on which they were modelled.

Challenges of data quality were encountered. On an average session, 14 or 15 sensors (of 16) provided EEG signals that could be analysed, the remainder lost due to issues with contact reliability with particular scalp locations and age cohorts. Certain sessions were evaluated as too noisy for inclusion in grand average analyses and early behavioural sessions proved more variable than later ones. Since this study was completed, incremental improvements to the headset, tablet-based app and participant familiarisation procedures have been made that have increased signal quality $(89,90)$.

While the focus of this paper is on ageing, and cognitive functions of relevance to Alzheimer's disease and other pathologies underlying dementia, this suite of tools can also 
include additional tasks (e.g., emotional face processing, passive auditory oddball) suitable for use in mood disorders, psychosis (110), and measurement of treatment response in psychiatry $(89,111)$.

Advances in wearable electronics, dry sensors and userfacing interactive technologies enable EEG as an easy-touse affordable biomarker of cognition, grounded directly in brain function. Decades of scientific literature support EEG as an emerging translational biomarker for disease cases in neuropsychiatric (schizophrenia, depression) (20, 112, 113) and neurodegenerative (e.g., Alzheimer's) disease (114-116). Sampling a broad suite of cognitive functions (including memory, attention, and executive function) offers coverage of multiple cognitive domains, which has greater predictive accuracy for disease progression $(117,118)$. Cloud computing can securely collect data from distributed locations, automatically evaluate quality, and use machine learning techniques to derive composite markers based on neural activity and behavioural performance from single and multiple cognitive domains (119). These innovations in technology, supported by scientific literature, make it possible to use large-scale longitudinal sampling of real-world data, to support potential future use-cases in early detection, personalised medicine, progression tracking, and measurement of treatment response for neuropsychiatric disorders.

\section{DATA AVAILABILITY STATEMENT}

The datasets presented in this article are not readily available because the data collected using the Cumulus Neuroscience platform is commercially sensitive and contains proprietary information. Requests to access supporting data will be considered from bona fide researchers upon reasonable request. Requests to access the datasets should be directed to alison@cumulusneuro.com.

\section{REFERENCES}

1. Brietzke E, Hawken ER, Idzikowski M, Pong J, Kennedy SH, Soares $\mathrm{CN}$. Integrating digital phenotyping in clinical characterization of individuals with mood disorders. Neurosci Biobehav Rev. (2019) 104:223-30. doi: 10.1016/j.neubiorev.2019.07.009

2. Carpenter G, Harbin HT, Smith RL, Hornberger J, Nash DB. A promising new strategy to improve treatment outcomes for patients with depression. Popul Health Manage. (2019) 22:223-8. doi: 10.1089/pop.2018.0101

3. Ermers NJ, Hagoort K, Scheepers FE. The predictive validity of machine learning models in the classification and treatment of major depressive disorder: state of the art and future directions. Front Psychiatry. (2020) 11:472. doi: 10.3389/fpsyt.2020.00472

4. Gillan CM, Whelan R. What big data can do for treatment in psychiatry. Curr Opin Behav Sci. (2017) 18:34-42. doi: 10.1016/j.cobeha.2017. 07.003

5. Jollans L, Whelan R. Neuromarkers for mental disorders: harnessing population neuroscience. Front Psychiatry. (2018) 9:242. doi: $10.3389 /$ fpsyt.2018.00242

6. Newson JJ, Thiagarajan TC. EEG frequency bands in psychiatric disorders : a review of resting state studies. Front Hum Neurosci. (2019) 12:521. doi: 10.3389/fnhum.2018.00521

\section{ETHICS STATEMENT}

The studies involving human participants were reviewed and approved by Queen's University Belfast Faculty Research Ethics Committee (EPS). The patients/participants provided their written informed consent to participate in this study.

\section{AUTHOR CONTRIBUTIONS}

$\mathrm{EM}, \mathrm{BMu}, \mathrm{BMc}, \mathrm{PP}$, and $\mathrm{AB}$ contributed to the conception and design of the study and paper. $A B$ performed data collection. EM, LR-D, HN, MI, JD, FB, BMu, and $\mathrm{AB}$ performed analysis and interpretation. $\mathrm{EM}, \mathrm{JD}, \mathrm{BMu}$, and $\mathrm{AB}$ wrote the manuscript. LR-D, HN, and MI wrote sections of the manuscript. All authors critically revised the manuscript and approve the submitted version.

\section{FUNDING}

The study on which this paper is based was funded by the Innovate UK Biomedical Catalyst programme (Grant Number: IUK 102862). LR-D was supported by Science Foundation Ireland (18/IF/6272) and the European Union's Horizon 2020 research and innovation programme under the Marie Skłodowska-Curie grant agreement No. 893823.

\section{ACKNOWLEDGMENTS}

The authors wish to thank Liam Watson and Aoife Sweeney for their part in data collection and Weronika JaworowskaBialko for her contributions to usability analysis. We also extend our gratitude to all our participants who gave up their time so generously to take part in this 12 -week study. We would like to thank Xi Jiang and Albert Yang for their helpful and constructive feedback during review.

7. Russ TC, Woelbert E, Davis KAS, Hafferty JD, Ibrahim Z, Inkster B, et al. How data science can advance mental health research. Nat Hum Behav. (2019) 3:24-32. doi: 10.1038/s41562-018-0470-9

8. Clapp WC, Hamm JP, Kirk IJ, Teyler TJ. Translating longterm potentiation from animals to humans: a novel method for noninvasive assessment of cortical plasticity. Biol Psychiatry. (2012) 71:496-502. doi: 10.1016/j.biopsych.2011.08.021

9. Drinkenburg WHIM, Ruigt GSF, Ahnaou A. Pharmaco-EEG studies in animals: an overview of contemporary translational applications. Neuropsychobiology. (2015) 72:151-64. doi: 10.1159/000442210

10. Leiser SC, Dunlop J, Bowlby MR, Devilbiss DM. Aligning strategies for using EEG as a surrogate biomarker: a review of preclinical and clinical research. Biochem Pharmacol. (2011) 81:1408-21. doi: 10.1016/j.bcp.2010.10.002

11. Atkinson RJ, Michie PT, Schall U. Duration mismatch negativity and P3a in first-episode psychosis and individuals at ultra-high risk of psychosis. Biol Psychiatry. (2012) 71:98-104. doi: 10.1016/j.biopsych.2011.08.023

12. Erickson MA, Ruffle A, Gold JM. A meta-analysis of mismatch negativity in schizophrenia: from clinical risk to disease specificity and progression. Biol Psychiatry. (2016) 79:980-7. doi: 10.1016/j.biopsych.2015.08.025

13. Hamilton HK, Boos AK, Mathalon DH. Electroencephalography and eventrelated potential biomarkers in individuals at clinical high risk for psychosis. Biol Psychiatry. (2020) 88:294-303. doi: 10.1016/j.biopsych.2020.04.002 
14. Light GA, Naatanen R. Mismatch negativity is a breakthrough biomarker for understanding and treating psychotic disorders. Proc Natl Acad Sci USA. (2013) 110:15175-6. doi: 10.1073/pnas.1313287110

15. Näätänen R, Todd J, Schall U. Mismatch negativity (MMN) as biomarker predicting psychosis in clinically at-risk individuals. Biol Psychol. (2016) 116:36-40. doi: 10.1016/j.biopsycho.2015.10.010

16. Nagai T, Tada M, Kirihara K, Araki T, Jinde S, Kasai K. Mismatch negativity as a "translatable" brain marker toward early intervention for psychosis: a review. Front Psychiatry. (2013) 4:115. doi: 10.3389/fpsyt.2013.00115

17. Perez VB, Roach BJ, Woods SW, Srihari VH, McGlashan TH, Ford JM, et al. Chapter 10 - Early auditory gamma-band responses in patients at clinical high risk for schizophrenia. In: Başar E, Başar-Eroĝlu C, Özerdem A, Rossini PM, Yener GG, editors. Application of Brain Oscillations in Neuropsychiatric Diseases: Selected Papers from "Brain Oscillations in Cognitive Impairment and Neurotransmitters”, Vol. 62. Istanbul: Elsevier (2013). p. 1-375.

18. Perez VB, Woods SW, Roach BJ, Ford JM, McGlashan TH, Srihari VH, et al. Automatic auditory processing deficits in schizophrenia and clinical high-risk patients: forecasting psychosis risk with mismatch negativity. Biol Psychiatry. (2014) 75:459-69. doi: 10.1016/j.biopsych.2013.07.038

19. Normann C, Schmitz D, Fürmaier A, Döing C, Bach M. Long-Term plasticity of visually evoked potentials in humans is altered in major depression. Biol Psychiatry. (2007) 62:373-80. doi: 10.1016/j.biopsych.2006.10.006

20. Olbrich S, van Dinteren R, Arns M. Personalized medicine: review and perspectives of promising baseline EEG biomarkers in major depressive disorder and attention deficit hyperactivity disorder. Neuropsychobiology. (2015) 72:229-40. doi: 10.1159/000437435

21. Stewart JL, Bismark AW, Towers DN, Coan JA, Allen JJB. Resting frontal EEG asymmetry as an endophenotype for depression risk: sex-specific patterns of frontal brain asymmetry. J Abnorm Psychol. (2010) 119:50212. doi: $10.1037 / \mathrm{a} 0019196$

22. Babiloni C, Lizio R, Del Percio C, Marzano N, Soricelli A, Salvatore E, et al. Cortical sources of resting state EEG rhythms are sensitive to the progression of early stage Alzheimer's disease. J Alzheimers Dis. (2013) 34:1015-35. doi: 10.3233/JAD-121750

23. Choi J, Ku B, You YG, Jo M, Kwon M, Choi Y, et al. Resting-state prefrontal EEG biomarkers in correlation with MMSE scores in elderly individuals. Sci Rep. (2019) 9:10468. doi: 10.1038/s41598-019-46789-2

24. Ghorbanian P, Devilbiss DM, Verma A, Bernstein A, Hess T, Simon AJ, et al. Identification of resting and active state EEG features of alzheimer's disease using discrete wavelet transform. Ann Biomed Eng. (2013) 41:124357. doi: 10.1007/s10439-013-0795-5

25. Lai CL, Lin RT, Liou LM, Liu CK. The role of event-related potentials in cognitive decline in Alzheimer's disease. Clin Neurophysiol. (2010) 121:1949. doi: 10.1016/j.clinph.2009.11.001

26. Musaeus CS, Nielsen MS, Østerbye NN, Høgh P. Decreased parietal beta power as a sign of disease progression in patients with mild cognitive impairment. J Alzheimers Dis. (2018) 65:475-87. doi: 10.3233/JAD-180384

27. Parra MA, Ascencio LL, Urquina HF, Manes F, Ibáñez AM. P300 and neuropsychological assessment in mild cognitive impairment and alzheimer dementia. Front Neurol. (2012) 3:172. doi: 10.3389/fneur.2012.00172

28. Smailovic U, Jelic V. Neurophysiological markers of alzheimer's disease: quantitative EEG approach. Neurol Ther. (2019) 8:37-55. doi: 10.1007/s40120-019-00169-0

29. Tóth B, File B, Boha R, Kardos Z, Hidasi Z, Gaál ZA, et al. EEG network connectivity changes in mild cognitive impairment - Preliminary results. Int J Psychophysiol. (2014) 92:1-7. doi: 10.1016/j.ijpsycho.2014.02.001

30. Borghini G, Astolfi L, Vecchiato G, Mattia D, Babiloni F. Measuring neurophysiological signals in aircraft pilots and car drivers for the assessment of mental workload, fatigue and drowsiness. Neurosci Biobehav Rev. (2014) 44:58-75. doi: 10.1016/j.neubiorev.2012.10.003

31. Wilson GF, Russell CA, Monnin JW, Estepp JR, Christensen JC. How does day-to-day variability in psychophysiological data affect classifier accuracy? Proc Hum Fact Ergonom Soc. (2010) 1:264-8. doi: 10.1177/154193121005400317

32. Duke Han S, Nguyen CP, Stricker NH, Nation DA. Detectable neuropsychological differences in early preclinical alzheimer's disease: a meta-analysis. Neuropsychol Rev. (2017) 27:30525. doi: 10.1007/s11065-017-9366-0
33. Hassenstab J, Ruvolo D, Jasielec M, Xiong C, Grant E, Morris JC. Absence of practice effects in preclinical Alzheimer's disease. Neuropsychology. (2015) 29:940-8. doi: 10.1037/neu0000208

34. Binder LM, Iverson GL, Brooks BL. To err is human: "abnormal" neuropsychological scores and variability are common in healthy adults. Arch Clin Neuropsychol. (2009) 24:31-46. doi: 10.1093/arclin/acn001

35. Cooley SA, Heaps JM, Bolzenius JD, Salminen LE, Baker LM, Scott $\mathrm{SE}$, et al. Longitudinal change in performance on the montreal cognitive assessment in older adults. Clin Neuropsychol. (2015) 29:824-35. doi: 10.1080/13854046.2015.1087596

36. Falleti M, Maruff P, Collie A, Darby D. Practice effects associated with the repeated assessment of cognitive function using the CogState battery at 10-minute, one week and one month test-retest intervals. J Clin Exp Neuropsychol. (2006) 28:1095-112. doi: 10.1080/13803390500205718

37. Goldberg TE, Harvey PD, Wesnes KA, Snyder PJ, Schneider LS. Practice effects due to serial cognitive assessment: implications for preclinical Alzheimer's disease randomized controlled trials. Alzheimers Dement Diag Assess Dis Monitor. (2015) 1:103-11. doi: 10.1016/j.dadm.2014.11.003

38. Mario B, Massimiliano M, Chiara M, Alessandro S, Antonella C, Gianfranco F. White-coat effect among older patients with suspected cognitive impairment: prevalence and clinical implications. Int J Geriatr Psychiatry. (2009) 24:509-17. doi: 10.1002/gps.2145

39. Sliwinski MJ, Mogle JA, Hyun J, Munoz E, Smyth JM, Lipton RB. Reliability and validity of ambulatory cognitive assessments. Assessment. (2018) 25:1430. doi: $10.1177 / 1073191116643164$

40. Brose A, Schmiedek F, Lövdén M, Lindenberger U. Daily variability in working memory is coupled with negative affect: the role of attention and motivation. Emotion. (2012) 12:605-17. doi: 10.1037/a0024436

41. Brose A, Lövdén M, Schmiedek F. Daily fluctuations in positive affect positively co-vary with working memory performance. Emotion. (2014) 14:1-6. doi: 10.1037/a0035210

42. Hess TM, Ennis GE. Age differences in the effort and costs associated with cognitive activity. J Gerontol Ser B Psychol Sci Soc Sci. (2012) 67:44755. doi: 10.1093/geronb/gbr129

43. Metternich B, Schmidtke K, Hüll M. How are memory complaints in functional memory disorder related to measures of affect, metamemory and cognition? J Psychosomat Res. (2009) 66:435-44. doi: 10.1016/j.jpsychores.2008.07.005

44. Stawski RS, Sliwinski MJ, Smyth JM. Stress-related cognitive interference predicts cognitive function in old age. Psychol Aging. (2006) 21:53544. doi: 10.1037/0882-7974.21.3.535

45. Hashemi A, Pino LJ, Moffat G, Mathewson KJ, Aimone C, Bennett PJ, et al. Characterizing population EEG dynamics throughout adulthood. ENeuro. (2016) 3:1-13. doi: 10.1523/ENEURO.0275-16.2016

46. Cormack FK, Taptiklis N, Abbott RA, Anatürk M, Cartland I, Coppieters $\mathrm{L}$, et al. Changes to validity of online cognitive assessment in young and older adults: a comparison to supervised testing using the cantab battery. Alzheimers Dement. (2016) 12:P286-7. doi: 10.1016/j.jalz.2016. 06.520

47. Lancaster C, Koychev I, Blane J, Chinner A, Chatham C, Taylor K, et al. Gallery game: smartphone-based assessment of long-term memory in adults at risk of Alzheimer's disease. J Clin Exp Neuropsychol. (2020) 42:32943. doi: 10.1080/13803395.2020.1714551

48. Moore RC, Swendsen J, Depp CA. Applications for self-administered mobile cognitive assessments in clinical research: a systematic review. Int J Methods Psychiatr Res. (2017) 26:e1562. doi: 10.1002/mpr.1562

49. Resnick HE, Lathan CE. From battlefield to home: a mobile platform for assessing brain health. MHealth. (2016) 2:30. doi: $10.21037 /$ mhealth.2016.07.02

50. Rogers JM, Johnstone SJ, Aminov A, Donnelly J, Wilson PH. Test-retest reliability of a single-channel, wireless EEG system. Int J Psychophysiol. (2016) 106:87-96. doi: 10.1016/j.ijpsycho.2016.06.006

51. Wong SWH, Chan RHM, Mak JN. Spectral modulation of frontal EEG during motor skill acquisition: a mobile EEG study. Int J Psychophysiol. (2014) 91:16-21. doi: 10.1016/j.ijpsycho.2013.09.004

52. Badcock NA, Mousikou P, Mahajan Y, De Lissa P, Thie J, McArthur G. Validation of the emotiv EPOC® EEG gaming systemfor measuring research quality auditory ERPs. PeerJ. (2013) 2013:e38. doi: 10.7717/peerj.38 
53. Badcock NA, Preece KA, de Wit B, Glenn K, Fieder N, Thie J, et al. Validation of the emotiv EPOC EEG system for research quality auditory event-related potentials in children. PeerJ. (2015) 3:e907. doi: 10.7717/peerj.907

54. Krigolson OE, Williams CC, Norton A, Hassall CD, Colino FL. Choosing MUSE: validation of a low-cost, portable EEG system for ERP research. Front Neurosci. (2017) 11:109. doi: 10.3389/fnins.2017.00109

55. Kuziek JWP, Shienh A, Mathewson KE. Transitioning EEG experiments away from the laboratory using a Raspberry Pi 2. J Neurosci Methods. (2017) 277:75-82. doi: 10.1016/j.jneumeth.2016.11.013

56. Lumsden J, Edwards EA, Lawrence NS, Coyle D, Munaf,ò MR. Gamification of cognitive assessment and cognitive training: a systematic review of applications and efficacy. JMIR Ser Games. (2016) 4:e11. doi: 10.2196/games.5888

57. Coughlan G, Coutrot A, Khondoker M, Minihane AM, Spiers H, Hornberger M. Toward personalized cognitive diagnostics of at-geneticrisk Alzheimer's disease. Proc Natl Acad Sci USA. (2019) 116:928592. doi: 10.1073/pnas.1901600116

58. Herrmann CS, Knight RT. Mechanisms of human attention: eventrelated potentials and oscillations. Neurosci Biobehav Rev. (2001) 25:46576. doi: 10.1016/S0149-7634(01)00027-6

59. Polich J, Kok A. Cognitive and biological determinants of P300: an integrative review. Biol Psychol. (1995) 41:10346. doi: 10.1016/0301-0511(95)05130-9

60. Twomey DM, Murphy PR, Kelly SP, O'Connell RG. The classic P300 encodes a build-to-threshold decision variable. Euro J Neurosci. (2015) 42:163643. doi: 10.1111/ejn.12936

61. Woods DL, Wyma JM, Yund EW, Herron TJ, Reed B. Age-related slowing of response selection and production in a visual choice reaction time task. Front Hum Neurosci. (2015) 9:193. doi: 10.3389/fnhum.2015.00193

62. Fjell AM, Walhovd KB. P300 and neuropsychological tests as measures of aging: scalp topography and cognitive changes. Brain Topogr. (2001) 14:25-40. doi: 10.1023/A:1012563605837

63. Pavarini SCI, Brigola AG, Luchesi BM, Souza ÉN, Rossetti ES, Fraga FJ, et al. On the use of the P300 as a tool for cognitive processing assessment in healthy aging: a review. Dement Neuropsychol. (2018) 12:111. doi: 10.1590/1980-57642018dn12-010001

64. van Dinteren R, Arns M, Jongsma MLA, Kessels RPC. P300 development across the lifespan: a systematic review and meta-analysis. PLoS ONE. (2014) 9:e0087347. doi: 10.1371/journal.pone.0087347

65. Yeung N, Botvinick MM, Cohen JD. The neural basis of error detection: conflict monitoring and the error-related negativity. Psychol Rev. (2004) 111:931-59. doi: 10.1037/0033-295X.111.4.931

66. Nieuwenhuis S, Ridderinkhof KR, Blom J, Band GPH, Kok A. Errorrelated brain potentials are differentially related to awareness of response errors: evidence from an antisaccade task. Psychophysiology. (2001) 38:75260. doi: 10.1111/1469-8986.3850752

67. Hoffmann S, Falkenstein M. Aging and error processing: age related increase in the variability of the error-negativity is not accompanied by increase in response variability. PLOS ONE. (2011) 6:e017482. doi: 10.1371/journal.pone.0017482

68. Dong S, Reder LM, Yao Y, Liu Y, Chen F. Individual differences in working memory capacity are reflected in different ERP and EEG patterns to task difficulty. Brain Res. (2015) 1616:146-56. doi: 10.1016/j.brainres.2015. 05.003

69. Bopp KL, Verhaeghen P. Aging and n-back performance: a metaanalysis. J Gerontol Ser B. (2018) 75:229-40. doi: 10.1093/geronb/ gby024

70. Grady C. The cognitive neuroscience of ageing. Nat Rev Neurosci. (2012) 13:491-505. doi: $10.1038 / \mathrm{nrn} 3256$

71. Mecklinger A. On the modularity of recognition memory for object form and spatial location: a topographic ERP analysis. Neuropsychologia. (1998) 36:441-60. doi: 10.1016/S0028-3932(97)00128-0

72. Alloway CED, Ogilvie RD, Shapiro CM. The alpha attenuation test: assessing excessive daytime sleepiness in narcolepsy-cataplexy. Sleep. (1997) 20:25866. doi: 10.1093/sleep/20.4.258

73. Barry RJ, Rushby J, Wallace M, Clarke A, Johnstone S, Zlojutro I. Caffeine effects on resting-state arousal. Clin Neurophysiol. (2005) 116:2693700. doi: 10.1016/j.clinph.2005.08.008
74. Rossini PM, Rossi S, Babiloni C, Polich J. Clinical neurophysiology of aging brain: from normal aging to neurodegeneration. Progr Neurobiol. (2007) 83:375-400. doi: 10.1016/j.pneurobio.2007.07.010

75. Stampi C, Stone P, Michimori A. A new quantitative method for assessing sleepiness: the alpha attenuation test. Work Stress. (1995) 9:36876. doi: 10.1080/02678379508256574

76. Nasreddine ZS, Phillips NA, Bédirian V, Charbonneau S, Whitehead V, Collin I, et al. The montreal cognitive assessment, MoCA: a brief screening tool for mild cognitive impairment. J Am Geriatr Soc. (2005) 53:6959. doi: 10.1111/j.1532-5415.2005.53221.x

77. Coen RF, Cahill R, Lawlor BA. Things to watch out for when using the montreal cognitive assessment (MoCA). Int J Geriatr Psychiatry. (2011) 26:107-8. doi: 10.1002/gps.2471

78. Kenny RA, Coen RF, Frewen J, Donoghue OA, Cronin H, Savva GM. Normative values of cognitive and physical function in older adults: findings from the irish longitudinal study on ageing. J Am Geriatr Soc. (2013) 61:S279-90. doi: 10.1111/jgs.12195

79. Brooke J. SUS: a "quick and dirty" usability scale. In: Jordan PW, Thomas B, Weerdmeester BA, McClelland IL, editors. Usability Evaluation in Industry. London: Taylor and Francis (1996). p. 189-94.

80. McEvoy K, Hasenstab K, Senturk D, Sanders A, Jeste SS. Physiologic artifacts in resting state oscillations in young children: methodological considerations for noisy data. Brain Imag Behav. (2015) 9:104-14. doi: 10.1007/s11682-014-9343-7

81. Chaudhry SI, Mattera JA, Curtis JP, Spertus JA, Herrin J, Lin Z, et al. Telemonitoring in patients with heart failure. N Engl J Med. (2010) 363:23019. doi: 10.1056/NEJMoa1010029

82. Ong MK, Romano PS, Edgington S, Aronow HU, Auerbach AD, Black $\mathrm{JT}$, et al. Effectiveness of remote patient monitoring after discharge of hospitalized patients with heart failure. JAMA Intern Med. (2016) 176:310. doi: 10.1001/jamainternmed.2015.7712

83. Sajatovic M, Velligan DI, Weiden PJ, Valenstein MA, Ogedegbe G. Measurement of psychiatric treatment adherence. J Psychosomat Res. (2010) 69:591-9. doi: 10.1016/j.jpsychores.2009.05.007

84. Argent R, Daly A, Caulfield B. Patient involvement with home-based exercise programs: can connected health interventions influence adherence? JMIR MHealth UHealth. (2018) 6:e47. doi: 10.2196/mhealth.8518

85. Maguire R, Fox PA, McCann L, Miaskowski C, Kotronoulas G, Miller M, et al. The eSMART study protocol: a randomised controlled trial to evaluate electronic symptom management using the advanced symptom management system (ASyMS) remote technology for patients with cancer. BMJ Open. (2017) 7:e015016. doi: 10.1136/bmjopen-2016-015016

86. Masterson Creber RM, Hickey KT, Maurer MS. Gerontechnologies for older patients with heart failure: what is the role of smartphones, tablets, and remote monitoring devices in improving symptom monitoring and self-care management? Current Cardiovasc Risk Rep. (2016) 10:30. doi: 10.1007/s12170-016-0511-8

87. Stone AA, Shiffman S, Schwartz JE, Broderick JE, Hufford MR. Patient compliance with paper and electronic diaries. Control Clin Trials. (2003) 24:182-99. doi: 10.1016/S0197-2456(02)00320-3

88. Bangor A, Kortum PT, Miller JT. An empirical evaluation of the system usability scale. Int J Hum Comput Interact. (2008) 24:57494. doi: 10.1080/10447310802205776

89. Barbey F, Dyer JF, McWilliams EC, Nolan H, Murphy B. Conventional wet eeg vs dry-sensor wireless eeg: comparing signal reliability through measures of neuronal integrity. In: Advances in Alzheimer's and Parkinson's Therapies: An AAT-AD/PD Focus Meeting (2020). Available online at: https://aat-adpd. kenes.com/

90. Murphy B, Barbey F, Buick AR, Dyer JF, Farina F, McGuinness $B$, et al. Replicating lab electrophysiology with older users in the home, using gamified dry EEG. Alzheimers Dement. (2019) 15:P867. doi: 10.1016/j.jalz.2019.06.4606

91. Reingold EM, Charness N, Pomplun M, Stampe DM. Visual span in expert chess players: evidence from eye movements. Psychol Sci. (2001) 12:4855. doi: 10.1111/1467-9280.00309

92. Colom R, Ramon FJ, Abad FJ, Shih PC, Privado J, Froufe M, et al. Adaptive n-back training does not improve fluid intelligence at the construct level: gains on individual tests suggest that training may enhance visuospatial 
processing. Intelligence. (2013) 41:712-27. doi: 10.1016/j.intell.2013. 09.002

93. Hassenstab J, Monsell SE, Mock C, Roe CM, Cairns NJ, Morris JC, et al. Neuropsychological markers of cognitive decline in persons with Alzheimer disease neuropathology. I Neuropathol Exp Neurol. (2015) 74:1086-92. doi: 10.1097/NEN.000000000 0000254

94. Baker JE, Bruns L, Hassenstab J, Masters CL, Maruff P, Lim YY. Use of an experimental language acquisition paradigm for standardized neuropsychological assessment of learning: a pilot study in young and older adults. J Clin Exp Neuropsychol. (2019) 42:55-65. doi: 10.1080/13803395.2019.1665626

95. Lim YY, Baker JE, Bruns L, Mills A, Fowler C, Fripp J, et al. Association of deficits in short-term learning and $A \beta$ and hippocampal volume in cognitively normal adults. Neurology. (2020) 95:e2577-85. doi: 10.1212/WNL.0000000000010728

96. De Vos M, Gandras K, Debener S. Towards a truly mobile auditory braincomputer interface: exploring the P300 to take away. Int J Psychophysiol. (2014) 91:46-53. doi: 10.1016/j.ijpsycho.2013.08.010

97. Hairston WD, Whitaker KW, Ries AJ, Vettel JM, Bradford JC, Kerick SE, et al. Usability of four commercially-oriented EEG systems. J Neural Eng. (2014) 11:046018. doi: 10.1088/1741-2560/11/4/046018

98. Kam JWY, Griffin S, Shen A, Patel S, Hinrichs H, Heinze HJ, et al. Systematic comparison between a wireless EEG system with dry electrodes and a wired EEG system with wet electrodes. NeuroImage. (2019) 184:11929. doi: 10.1016/j.neuroimage.2018.09.012

99. Radüntz T, Meffert B. User experience of 7 mobile electroencephalography devices: comparative study. JMIR MHealth UHealth. (2019) 7:1-18. doi: 10.2196/14474

100. Debener S, Minow F, Emkes R, Gandras K, de Vos M. How about taking a low-cost, small, and wireless EEG for a walk? Psychophysiology. (2012) 49:1617-21. doi: 10.1111/j.1469-8986.2012.01471.x

101. Stopczynski A, Stahlhut C, Larsen JE, Petersen MK, Hansen LK. The smartphone brain scanner: a portable real-time neuroimaging system. PLoS ONE. (2014) 9:e0086733. doi: 10.1371/journal.pone.0086733

102. Duvinage M, Castermans T, Petieau M, Hoellinger T, Cheron G, Dutoit T. Performance of the emotiv Epoc headset for P300-based applications. BioMed Eng Online. (2013) 12:1-15. doi: 10.1186/1475-925X-12-56

103. Maskeliunas R, Damasevicius R, Martisius I, Vasiljevas M. Consumer grade EEG devices: are they usable for control tasks? PeerJ. (2016) 4:e1746. doi: 10.7717/peerj.1746

104. Porcaro C, Balsters JH, Mantini D, Robertson IH, Wenderoth N. P3b amplitude as a signature of cognitive decline in the older population: an EEG study enhanced by functional source separation. NeuroImage. (2019) 184:535-46. doi: 10.1016/j.neuroimage.2018.09.057

105. Larson MJ, Clayson PE, Keith CM, Hunt IJ, Hedges DW, Nielsen BL, et al. Cognitive control adjustments in healthy older and younger adults: conflict adaptation, the error-related negativity (ERN), and evidence of generalized decline with age. Biol Psychol. (2016) 115:5063. doi: 10.1016/j.biopsycho.2016.01.008

106. Grummett TS, Leibbrandt RE, Lewis TW, DeLosAngeles D, Powers DMW, Willoughby JO, et al. Measurement of neural signals from inexpensive, wireless and dry EEG systems. Physiol Measure. (2015) 36:1469. doi: 10.1088/0967-3334/36/7/1469

107. Hurlow J, Bliss DZ. Dry skin in older adults. Geriatr Nurs. (2011) 32:25762. doi: 10.1016/j.gerinurse.2011.03.003

108. Ishii R, Canuet L, Aoki $\mathrm{Y}$, Hata M, Iwase M, Ikeda S, et al. Healthy and pathological brain aging: from the perspective of oscillations, functional, connectivity, signal complexity. Neuropsychobiology. (2017) 75:151-61. doi: $10.1159 / 000486870$

109. Klimesch W. EEG alpha and theta oscillations reflect cognitive and memory performance: a review and analysis. Brain Res Rev. (1999) 29:16995. doi: 10.1016/S0165-0173(98)00056-3

110. Dyer JF, Barbey F, Barrett SL, Pickering EC, Buick AR, Mulholland C, et al. Gamified mobile EEG for early detection of psychotic disorders: identifying needs from clinicians and end-users. In: Nutt D, and Blier P, editors. British Association for Psychopharmacology Summer Meeting. Manchester (2019). p. A53.

111. Murphy B, Barbey F, Bianchi M, Buhl DL, Buick AR, Danyeli L, et al. Demonstration of a Novel Wireless EEG Platform to Detect the Acute and Long-Term Effects of Ketamine, in the Lab and in the Home. Glasgow: FENS (2020).

112. Maran M, Grent-'t-Jong T, Uhlhaas PJ. Electrophysiological insights into connectivity anomalies in schizophrenia: a systematic review. Neuropsychiatr Electrophysiol. (2016) 2:1-9. doi: 10.1186/s40810-016-0020-5

113. Randeniya R, Oestreich LKL, Garrido MI. Sensory prediction errors in the continuum of psychosis. Schizophren Res. (2018) 191:10922. doi: 10.1016/j.schres.2017.04.019

114. Al-Nuaimi AHH, Jammeh E, Sun L, Ifeachor E. Complexity measures for quantifying changes in electroencephalogram in alzheimer's disease. Complexity. (2018) 2018:22-4. doi: 10.1155/2018/8915079

115. Ferreira D, Jelic V, Cavallin L, Oeksengaard AR, Snaedal J, Høgh P, et al. Electroencephalography is a good complement to currently established dementia biomarkers. Dement Geriatr Cogn Disord. (2016) 42:80-92. doi: 10.1159/000448394

116. Horvath A, Szucs A, Csukly G, Sakovics A, Stefanics G, Kamondi A. EEG and ERP biomarkers of Alzheimer's disease: a critical review. Front. Biosci. (2018) 23:4587. doi: 10.2741/4587

117. Belleville S, Fouquet C, Hudon C, Zomahoun HTV, Croteau J. Neuropsychological measures that predict progression from mild cognitive impairment to alzheimer's type dementia in older adults: a systematic review and meta-analysis. Neuropsychol. Rev. (2017) 27:328-353. doi: 10.1007/s11065-017-9361-5

118. Chehrehnegar N, Nejati V, Shati M, Rashedi V, Lotfi M, Adelirad F, et al. Early detection of cognitive disturbances in mild cognitive impairment: a systematic review of observational studies. Psychogeriatrics. (2020) 20:21228. doi: 10.1111/psyg.12484

119. Murphy B, Aleni A, Belaoucha B, Dyer JF, Nolan H. Quantifying cognitive aging and performance with at-home gamified mobile EEG. In: 2018 International Workshop on Pattern Recognition in Neuroimaging (PRNI). Singapore (2018). p. 1-4. doi: 10.1109/PRNI.2018.8423954

Conflict of Interest: LR-D, AB, EM, JD, HN, MI, FB, and BMu are employees of the company Cumulus Neuroscience Ltd.

The remaining authors declare that the research was conducted in the absence of any commercial or financial relationships that could be construed as a potential conflict of interest.

Copyright $\odot 2021$ McWilliams, Barbey, Dyer, Islam, McGuinness, Murphy, Nolan, Passmore, Rueda-Delgado and Buick. This is an open-access article distributed under the terms of the Creative Commons Attribution License (CC BY). The use, distribution or reproduction in other forums is permitted, provided the original author(s) and the copyright owner(s) are credited and that the original publication in this journal is cited, in accordance with accepted academic practice. No use, distribution or reproduction is permitted which does not comply with these terms. 